See discussions, stats, and author profiles for this publication at: https://www.researchgate.net/publication/275578302

\title{
Dynamic Modeling and Analysis of a Remote Hybrid Power System with Pumped Hydro Storage
}

Article in International Journal of Energy Science · January 2013

Dol: 10.14355/ijes.2013.0305.05

CITATIONS

2 authors, including:

Tariq Iqbal

Memorial University of Newfoundland

348 PUBLICATIONS 3,841 CITATIONS

SEE PROFILE

Some of the authors of this publication are also working on these related projects:

Project

DOE Applications View project

Project NESTNET View project
READS

51 


\title{
Dynamic Modeling and Analysis of a Remote Hybrid Power System with Pumped Hydro Storage
}

\author{
Md. Rahimul Hasan Asif ${ }^{1}$, Tariq Iqbal ${ }^{2}$ \\ 1,2Faculty of Engineering and Applied Science, Memorial University of Newfoundland \\ St. John's, NL A1C 5S7, P.O. Box 4200, CANADA \\ ${ }^{1}$ mrha46@mun.ca; ${ }^{2}$ tariq@mun.ca
}

\begin{abstract}
In this research dynamic modeling of a remote hybrid power system and feasibility of a pumped hydro storage system is presented. Current hybrid system in Ramea, Newfoundland has an electrolyzer, storage and hydrogen generator system. This research proposes a pumped hydro storage as a replacement to the hydrogen system. Detailed MATLABSimulink modeling has been done for every component of the Ramea hybrid power system. Incorporation of a pumped hydro system and some lead acid batteries will eliminate the low turn around efficiency of the electrolyzer and hydrogen generator system. The system dynamic model presented here is fast, accurate and includes dynamic and supervisory controllers. The proposed real time supervisory controller algorithm observes the available surplus/missing power in the system and regulates pump/turbine and charging/discharging of the battery bank to maintain a stable system frequency. This paper presents dynamic model, supervisory controller design and algorithm, six case studies and detailed simulation results.
\end{abstract}

\section{Keywords}

Dynamic Modeling; Wind-diesel systems; Pumped Hydro Storage; Hybrid Power Systems; Renewable Energy

\section{Introduction}

Ramea is a small island located off the south coast of Newfoundland, Canada. In 2004, Ramea was selected as the first pilot project site for a Wind-Diesel hydrogen hybrid power system which was led by the Newfoundland and Labrador Hydro. The main objective of this project was to demonstrate substantial improvement of energy efficiency and reliability after incorporating Wind-Diesel Integrated Control System (WDICS) in the island's grid which can reduce the use of diesel power by hosting green renewable wind energy in remote and isolated location. This winddiesel pilot system is generating almost 1 million $\mathrm{kWh}$ of electricity and offsetting nearly 750 tons of greenhouse gas emissions per annum [1] [2].

Wind energy system in Ramea has six $65 \mathrm{~kW}$ Windmatic $15 \mathrm{~s}$ and three $100 \mathrm{~kW}$ NorthernPower100 wind turbines (WT). Three $925 \mathrm{~kW}$ Diesel engine generators (DEG) are used as the main power source. A Hydrogen Electrolyzer and Storage (HES) and a 250kW Hydrogen Powered Generator (HPG) have been installed to increase the renewable energy penetration. When wind power generation exceeds the load, the electrolyzer produces hydrogen from water electrolysis which is stored in the storage tanks. And when harnessed wind power is inadequate to supply the total load the stored hydrogen is fed into a HPG as a fuel which delivers electricity to the grid and maintains the stability [2]. This HES system produces hydrogen at $70 \%$ efficiency and HPG generates electricity at less than $35 \%$ efficiency. Overall it gives a poor turn around conversion efficiency that is less than $25 \%$ [3]. Ramea system has many operational issues due to its complexity. So far, it never operated as designed. Detailed information, analysis and dynamic simulation for the optimal size and site selection of a pumped hydro storage (PHS) system replacing the HES and HPG has been presented in Ref. [4]. It has been explained that almost $37 \%$ renewable energy fraction can be attained using a $150 \mathrm{~kW}$ PHS system with a $3932 \mathrm{~m}^{3}$ water reservoir at $63 \mathrm{~m}$ height on top of 'Man of War' hill [4]. Topographical map of that hill shows that it has $2000 \mathrm{~m}^{2}$ of area to build a $2 \mathrm{~m}$ high hydro storage reservoir. In Ref. [4] only $24 \mathrm{~s}$ of dynamic simulation had been presented as it took days of computer time to simulate $1 \mathrm{~min}$ of system operation. Moreover the simulation didn't converge in the time period of $11 \mathrm{~s}$ to $16 \mathrm{~s}$. Simple first order modeling of every system component can 


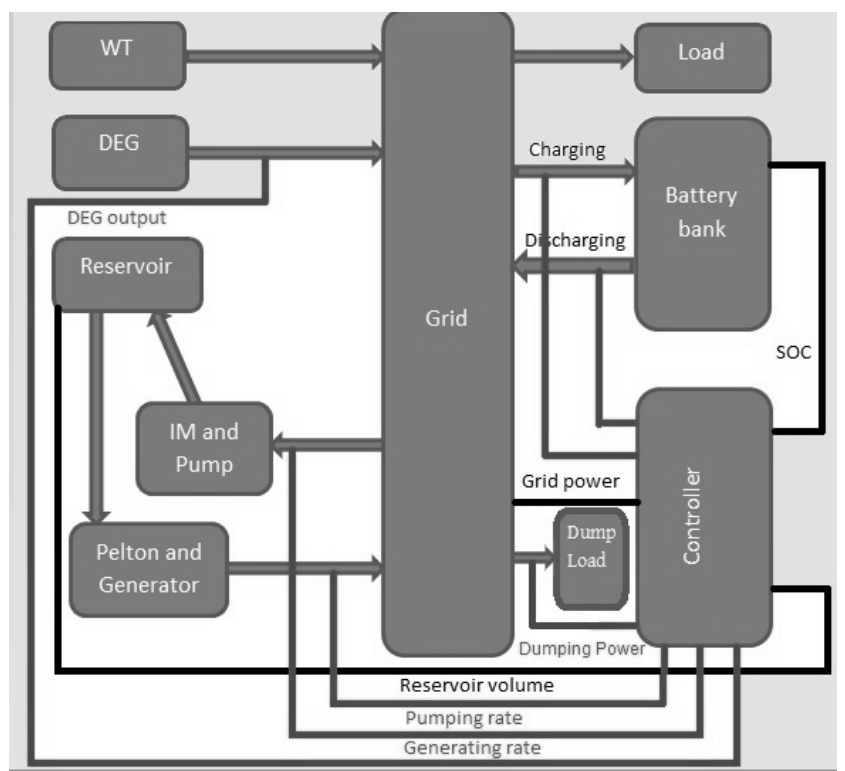

FIG. 1 BLOCK DIAGRAM OF RAMEA HYBRID POWER SYSTEM WITH A PROPOSED PUMPED HYDRO STORAGE SYSTEM, BATTERY BANK AND DUMP LOAD

considerably reduce the simulation time, make the analysis easier and gives fairly accurate solutions. Research [5] shows the system stability of a selfgoverning hybrid renewable power generation and storage system connected with isolated loads by timedomain simulations. As storage subsystems, that hybrid system had a battery bank (BB) and a flywheel system. Three mathematical models have been investigated for three different sets of operating points and disturbance conditions. But the presented mathematical subsystems are too simple where nonlinear efficiency, friction and response time are ignored and there is no controller in the model. The real challenge is to model practical subsystems with simple first order models juxtaposing all efficiencies, dynamic frictions, different time constants related to the subsystem parameters.

A simple, fast and novel method has been introduced in this research work to simulate system dynamics of Ramea hybrid power system with a proposed PHS. A block diagram of Ramea hybrid power system is shown in FIG. 1 Some system details may be found in [6]. A BB has been used to supply or store the intermittent power as induction motor (IM) and centrifugal pump (CP) or turbine and generator require some time to reach a certain rated operating point and have larger time constant than a battery bank. A controllable dump load (DL) has also been used to dump the excess power. The presented model has PID controllers with all its subsystems.
Characteristic data and parameters of the aforementioned WTs and DEG used in Ramea hybrid system are taken from the respective manufacturers. All other subsystem models e.g. CP, Pelton Wheel Turbine (PWT), BB have been created using first principle and data obtained from manufactures. In this study dynamic models with 1st order transfer functions (TF) are considered. Simulations have been done for one day (86400s) for six extreme cases. Detailed results and analyses are presented in the later part of this paper.

\section{Dynamic Modeling}

\section{i. Wind Speed Data}

Wind speed data $(1 \mathrm{~Hz})$ from the Prince Edward Island (PEI), Newfoundland, Canada is used. Average value of the data was adjusted to represent wind speed at Ramea. Two wind speed average have been considered here e.g. $2.9 \mathrm{~m} / \mathrm{s}$ and $13.75 \mathrm{~m} / \mathrm{s}$.

\section{ii. Load Data}

Ramea load data for two days is used from Ref. [4]. Two 24 hour load curves are used from the data array with averages of $303 \mathrm{~kW}$ and $800 \mathrm{~kW}$.

\section{iii. Wind Turbine Model}

WT power curves have been collected from the corresponding manufacturers. Power curve data was fitted with a 6th order polynomial.

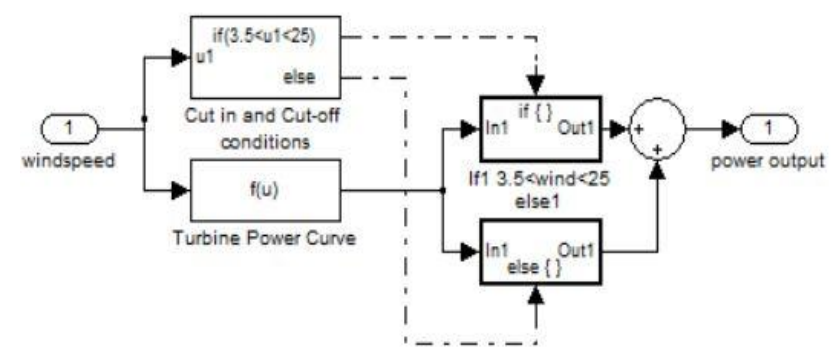

FIG. 2 WIND TURBINE POWER CURVE AND LIMITING CONDITIONS

As shown in FIG. 2 necessary cut in and cut out wind speed conditions have been applied in the WT model. Wind turbine time constants are used following the equation from the Ref. [7]:

$\mathrm{HwT} \cong 1.87$ * $\mathrm{PwT}^{0.0597}$

In Eq. (1) Hwt is the mechanical inertia time constant and $\mathrm{P}_{\mathrm{WT}}$ is the power of the WT in watts. So calculation gives $3.6 \mathrm{~s}$ for $65 \mathrm{~kW}$ Windmatic $15 \mathrm{~s}$ [8] and 3.7s for 100kW Northern Power 100 [9]. In FIG. 3 all WTs, load 


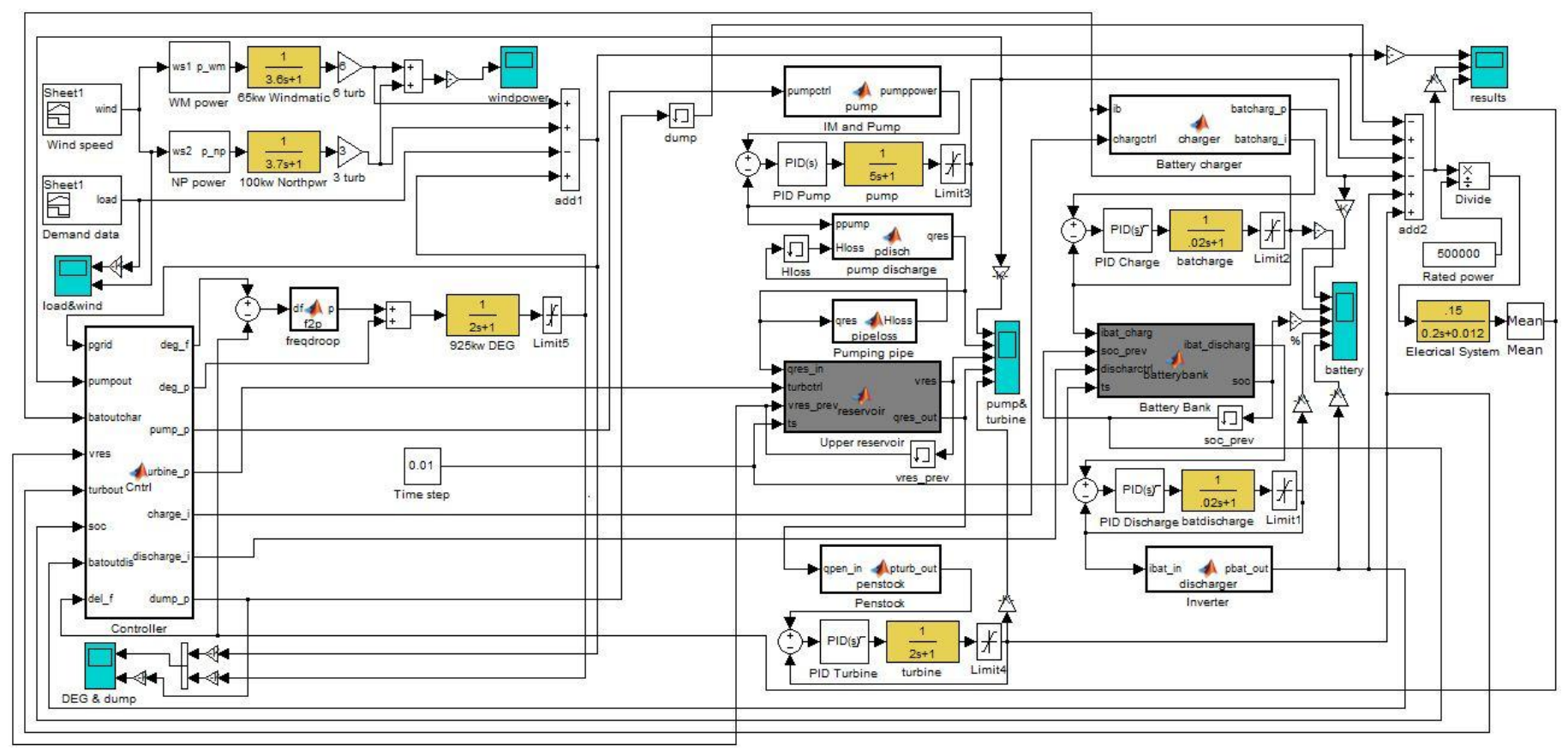

FIG. 3 SIMULINK - MATLAB EMBEDDED FUNCTION BLOCKS BASED DYNAMIC MODEL OF RAMEA HYBRID POWER SYSTEM WITH PUMPED HYDRO STORAGE, BATTERY BANK AND DUMP LOAD

demand and varying DEG output are connected with an adder 'add1'. Output of 'add1' represents the power available or lack in the grid which has to be managed by the PHS or BB.

\section{iv. Diesel Engine Generator Model}

DEG in Ramea has a rated output of $925 \mathrm{~kW}$. There are three DEG but only one is used at a time. A DEG can be operated down to $30 \%$ of its rated output i.e. the DEG can operate from $300 \mathrm{~kW}$ to $925 \mathrm{~kW}$. However, a DEG always keeps running at $300 \mathrm{~kW}$ (a minimum), whatever the case, to maintain a stable system frequency. Time constant of DEG is taken as it is used in Ref. [5] so TFDEG $=1 /(2 s+1)$. This value has been verified from the datasheet of a DEG of almost same rating. The acceleration time constant of DEG is calculated by the following Eq. (2),

$J=S_{n} \frac{T_{D E G}}{\omega_{n}^{2}}$

Here, $J$ is the moment of inertia; $\omega_{n}$ is the rated angular velocity, which equals $2 \pi \mathrm{f} ; S_{n}$ is the DEG nominal apparent power; TDEG is the acceleration time constant rated to $S_{n}$. In the datasheet of the DEG, J $=20 \mathrm{~kg} \cdot \mathrm{m}^{2}$. That results in the acceleration time constant of DEG of TDEG $\cong 2 \mathrm{~s}$. With this time constant this DEG needs about 10 s to reach its steady state value.

Frequency droop curve has been introduced considering that this DEG has a $\Delta \mathrm{P} / \Delta \mathrm{f}$ ratio of $300 \mathrm{~kW} / 1 \mathrm{~Hz}$. The MATLAB code used here is, $\mathrm{dpu}=1-(62-(\mathrm{df}+60)) / 2$

In Eq. (3) dpu is per unit excess power that will be injected to balance out the frequency deviation, df in the grid.

\section{v. Induction Motor and Centrifugal Pump Model}

Considering their individual characteristics IM and CP are modeled together in a block (IM and Pump block in FIG. 3). The $\mathrm{CP}$ takes relatively large time to respond to a sudden change than an IM. Comparing the starting time of a combination of IM and CP from Ref. [10], a 4000hp - 1000rpm pumping system takes approximately 2:30 minutes to reach its rated output. Here we assumed that a $200 \mathrm{hp}$ pumping system needs 30 s to settle down to its steady state. Therefore transfer function of this block is $\mathrm{TF}_{\mathrm{CP}}=1 /(5 \mathrm{~s}+1) . \mathrm{K}_{\mathrm{P}}=$ $0.4732, \mathrm{~K}_{\mathrm{I}}=0.3391$ and $\mathrm{K}_{\mathrm{D}}=0$ are used in PID controller of CP. Built in tuner of Simulink PID block has been used for this block as well as rest of the blocks in this model to determine suitable controller parameters. Efficiencies of IM and CP are considered as $95 \%$ and $80 \%$ respectively which gives a total efficiency of $75 \%$. Eq. (4) is used in MATLAB code to determine gres $=$ pumping water flow to reservoir.

qres $=($ ppump*pmeff $) /($ hres + Hloss $) *$ den $s * g$

Here, ppump $=$ power delivered to the pumping system which can vary from $30 \%$ to $100 \%$ of the rated output e.g. $100 \mathrm{~kW}$ to $300 \mathrm{~kW}$; pmeff $=75 \%$; hres $=63 \mathrm{~m}$ (height of the reservoir); Hloss = penstock friction loss; dens = 
$1000 \mathrm{kgm}^{-3}$ and $\mathrm{g}=9.81 \mathrm{~ms}^{-2}$.

\section{vi. Penstock Model}

Penstock is designed as Lpipe $=70 \mathrm{~m}$ in length and Dpipe $=0.3 \mathrm{~m}$ in diameter. Reynolds number is selected assuming that water flow is laminar inside the pipe. A minor loss coefficient for water meter is used here as klossco which is taken equal to 7 [11].

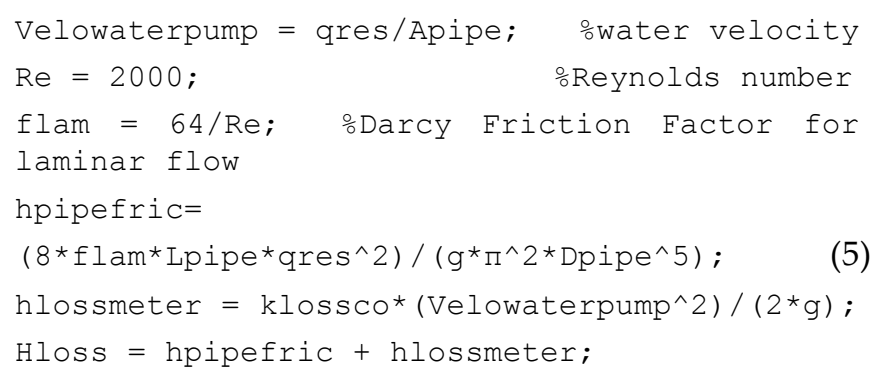

Eq. (5) used here is Darcy-Weisbach equation for friction inside the penstock [12]. Here Hloss is calculated in each step for new qres.

\section{vii. Water Reservoir Model}

The proposed water reservoir has a total volume of $4000 \mathrm{~m}^{3}$. In simulations initial volume is considered as $2000 \mathrm{~m}^{3}$. Pump action will be stopped if water volume exceeds $3950 \mathrm{~m}^{3}$ and turbine action will be terminated if water volume goes below $150 \mathrm{~m}^{3}$. Total water volume in the reservoir can be determined from water flows in both ways or from the height of water in the reservoir (see upper reservoir block in FIG. 3).

\section{viii. Turbine Model}

A $150 \mathrm{~kW}$ PWT has been used here which has very good partial flow efficiency as shown in FIG. 4 [13]. The blue curve here is for a twin jet setup. Synchronous generator and PWT are modeled together using a combined efficiency of $70 \%$ and time constant of $2 \mathrm{~s}$ as DEG. TF of this block is TFtuRB $=1 /(2 s+1) . K_{P}=0.4732$, $K_{I}=1.6955$ and $K_{D}=0$ are used in PID controller of PWT (turbine block in FIG. 3). The power output of the turbine generator block is as in Eq. (6)

pturb_out $=$ qpen_in*hres*dens*g*turbeff

Here, pturb_out $=$ turbine output power, qpen_in $=$ incoming water flow to the turbine and turbef $f=70 \%$ as turbine efficiency.

\section{ix. Battery Bank Model}

In an isolated grid BB used as storage provides fast response which makes them favorable to improve power quality and gain system reliability. A bank of
300 batteries has been used here each having a capacity of 200Ahr. Total 15 branches are connected in

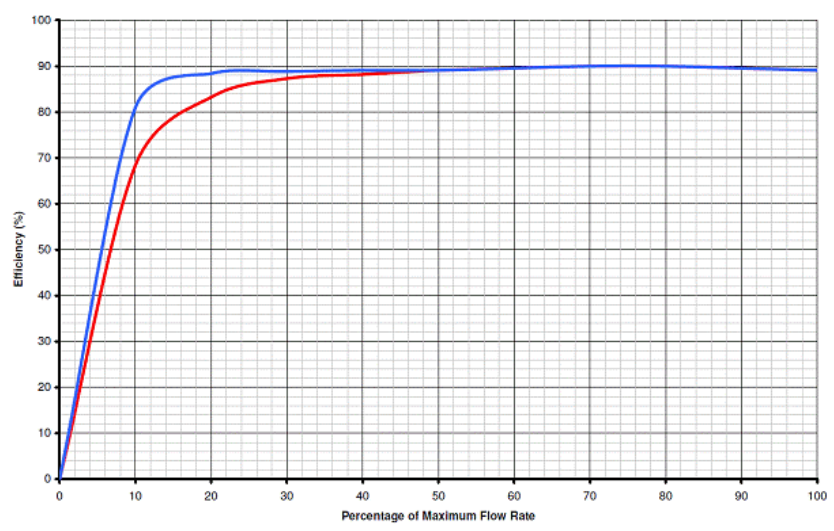

FIG. 4 PART FLOW EFFICIENCY OF A PELTON WHEEL TURBINE

parallel where each branch consists of 20 batteries in series delivering a DC battery bus voltage of $240 \mathrm{~V}$. A charging and a discharging block have been created to control the current and monitor the State of Charge (SOC) of the battery. A SLA battery should not be discharged when SOC goes down to $40 \%$. Total coulomb capacity can be determined from the calculations below in (7), (battery bank block in FIG. 3)

Total cap $=$ individual cap * 3600 * no. of branch

$$
=200 * 3600 * 15=10800000 \mathrm{C} \text { (at 100\% SOC) }
$$

So the BB operates from $100 \%$ SOC to $40 \%$ SOC (4320000C). For charging current a maximum $10 \%$ of the individual capacity will be allowed as in (8) where charge_i $=$ total charging current, ind_cap $=$ individual capacity and nbat_para $=$ no. of branches.

charge_i $=0.1$ * ind_cap * nbat_para

discharge_i $=0.33$ * ind_cap * nbat_para

A maximum of $72 \mathrm{~kW}$ surplus power can be utilized to charge the BB almost instantaneously. For a maximum power shortage of $234 \mathrm{~kW}$ can be supplied from the BB by discharging it to 'one third of the individual capacity'. In (9) discharge $i=$ total discharging current. In this model initial SOC is chosen as $70 \%$ which is equivalent to $7560000 \mathrm{C}$. While discharging, battery bank can be discharged at any rate below $0.33 \mathrm{CA}$ but that will affect the effective capacity of battery following the 'Peukert's law'.

$$
I t=C\left(\frac{C}{I H}\right)^{k-1}
$$

Here, 'I $I$ ' is the effective capacity at discharge rate of $I$, $H$ is the rated discharge time, in (hours), $k$ is the 
Peukert constant which is 1.2 for SLA battery. Along with this in this model the combined efficiency of battery and converters is considered as $80 \%$. Eq. (11) is used to calculate the power delivered (pbat_out) by the battery where v_bat $=240 \mathrm{~V}$, ibat_in $=$ total discharging current and bateff $=80 \%$.

pbat_out $=$ v_bat $*$ ibat_in $*$ bateff

$\mathrm{TF}$ of Battery Discharge block (FIG. 3 ) is $\mathrm{TF}_{\mathrm{BB}}=1 /(0.02 \mathrm{~s}$ +1 ). As SLA battery has a very fast response in the range of milliseconds [14], here modeled BB takes less than $100 \mathrm{~ms}$ to reach steady state. Coefficients for the PID controller of this block are $\mathrm{K}_{\mathrm{P}}=0.0001, \mathrm{~K}_{\mathrm{I}}=$ 213617.933 and $K_{D}=0$. The $B B$ will provide power while mechanical subsystems are starting up.

\section{x. Dump Load Model}

A 1MW (maximum) controllable dump load has been used to curtail the excess power from the grid while the wind speed is considerably high and/or the load demand is low. Maximum power dissipation in the dump load is $800 \mathrm{~kW}$ (in the case 2 where wind speed is high and load is low). A PWM controller can be used to dump the surplus power from the grid to the dump load. The dump load help reduce the frequency spikes in the grid.

\section{xi. Model of the Electrical System}

The system inertia constant $\mathrm{M}$ and load-damping constant D have been used same as in Ref. [5]. The gain has been changed from 1.0 to 0.15 as 1.0 makes the system too sensitive. TF of the electrical system has been considered as TFelec $=0.15 /(0.2 \mathrm{~s}+0.012)$. Therefore, $0.05 \mathrm{pu}$ power deviation will cause $0.01 \mathrm{pu}$ or $0.6 \mathrm{~Hz}$ frequency deviation (see electrical system block in FIG. 3).

\section{Supervisory Controller}

PID controllers have been used to control all individual subsystems. To determine the optimum coefficients for the PID controllers, Simulink built in PID tuner has been used. Limiters have been used to clip all out of range values. A simple flowchart of the algorithm used in this model as the supervisory controller is shown in FIG. 5. It is shown as a block 'controller' in the FIG. 3. DEG has the last priority to take control. Pump and Pelton wheel operate with the highest priority as per the requirement and $\mathrm{BB}$ compensates for the intermittent deviations due to the inertial delay of rotating mechanical devices. In each step supervisory controller keeps measuring the reservoir water volume, SOC and the grid power. When DEG takes control, a differential block measures the frequency deviation from the set value and according to the frequency droop characteristics curve of the DEG it adjusts its output power.

\section{Results: Six Case Studies}

For different conditions of wind speed and load six cases are proposed in Table 1. These six cases cover possible normal and extreme operation of the hybrid power system.

TABLE 1 SIX DIFFERENT CASES OF LOAD AND WIND SPEED

\begin{tabular}{|c|c|c|}
\hline Case & Load & Wind speed \\
\hline 1 & Low $(200 \mathrm{~kW}$ to $330 \mathrm{~kW})$ & Low $(0 \mathrm{~m} / \mathrm{s}$ to $9 \mathrm{~m} / \mathrm{s})$ \\
\hline 2 & Low $(200 \mathrm{~kW}$ to $330 \mathrm{~kW})$ & High $(10 \mathrm{~m} / \mathrm{s}$ to $20 \mathrm{~m} / \mathrm{s})$ \\
\hline 3 & High (590kW to $990 \mathrm{~kW})$ & Low $(0 \mathrm{~m} / \mathrm{s}$ to $9 \mathrm{~m} / \mathrm{s})$ \\
\hline 4 & High (590kW to $990 \mathrm{~kW})$ & $\operatorname{High}(10 \mathrm{~m} / \mathrm{s}$ to $20 \mathrm{~m} / \mathrm{s})$ \\
\hline 5 & $\begin{array}{c}\text { Abrupt load change } \\
\text { (500kW to } 700 \mathrm{~kW} \text { at } 200 \mathrm{~s} \\
\text { and vice versa at } 700 \mathrm{~s})\end{array}$ & Steady in midrange $(5 \mathrm{~m} / \mathrm{s})$ \\
\hline 6 & $\begin{array}{l}\text { Steady in midrange } \\
\qquad(500 \mathrm{~kW})\end{array}$ & $\begin{array}{c}\text { Abrupt wind speed change } \\
(8 \mathrm{~m} / \mathrm{s} \text { to } 11 \mathrm{~m} / \mathrm{s} \text { at } 200 \mathrm{~s} \text { and } \\
\text { vice versa at } 700 \mathrm{~s})\end{array}$ \\
\hline
\end{tabular}

Simulation of the developed system model shown in FIG. 3 has been done for one day i.e. 86400s. Site wind speed data and load data have been used [4]. Data is from the year 2001. Inspecting site wind speed data and load data the lowest 24 hours average load was found to be $303 \mathrm{~kW}$ on September 3, 2001 which is referred as 'Low load' in this paper. Load varies between $200 \mathrm{~kW}$ to $330 \mathrm{~kW}$ from 12:00:00AM to 11:59:59PM. And the highest load found in the year of 2001 is $800 \mathrm{~kW}$ on December 29, 2001 where load varied from $590 \mathrm{~kW}$ to $990 \mathrm{~kW}$ throughout the day. This is referred as 'High load' in this paper.

Observing all daily average of wind speed data it has been found that on September 17, 2001 a lowest daily average of wind speed was recorded which was $2.9 \mathrm{~m} / \mathrm{s}$ and wind speed stayed between $0 \mathrm{~m} / \mathrm{s}$ to $9 \mathrm{~m} / \mathrm{s}$. This is referred here as 'Low wind'. Highest daily average wind speed has been found to be $13.75 \mathrm{~m} / \mathrm{s}$ on February 26, 2001 where it varied between $10 \mathrm{~m} / \mathrm{s}$ to $20 \mathrm{~m} / \mathrm{s}$. This wind speed pattern is referred as 'High wind' in this paper. As an abrupt change of load, it is assumed that for a 1000s time period load changes to $700 \mathrm{~kW}$ from $500 \mathrm{~kW}$ at $\mathrm{t}=200 \mathrm{~s}$ and drops to $500 \mathrm{~kW}$ 
again at $\mathrm{t}=700 \mathrm{~s}$ while wind speed stays steady at $5 \mathrm{~m} / \mathrm{s}$. On the other hand, abrupt change of wind speed has been considered as a rise to $11 \mathrm{~m} / \mathrm{s}$ from $8 \mathrm{~m} / \mathrm{s}$ at $\mathrm{t}=200 \mathrm{~s}$ and again dropping back to $8 \mathrm{~m} / \mathrm{s}$ at $\mathrm{t}=700 \mathrm{~s}$. For this change the load has been assumed a constant at $500 \mathrm{~kW}$. Results for all six case studies with theses extreme conditions are presented below.

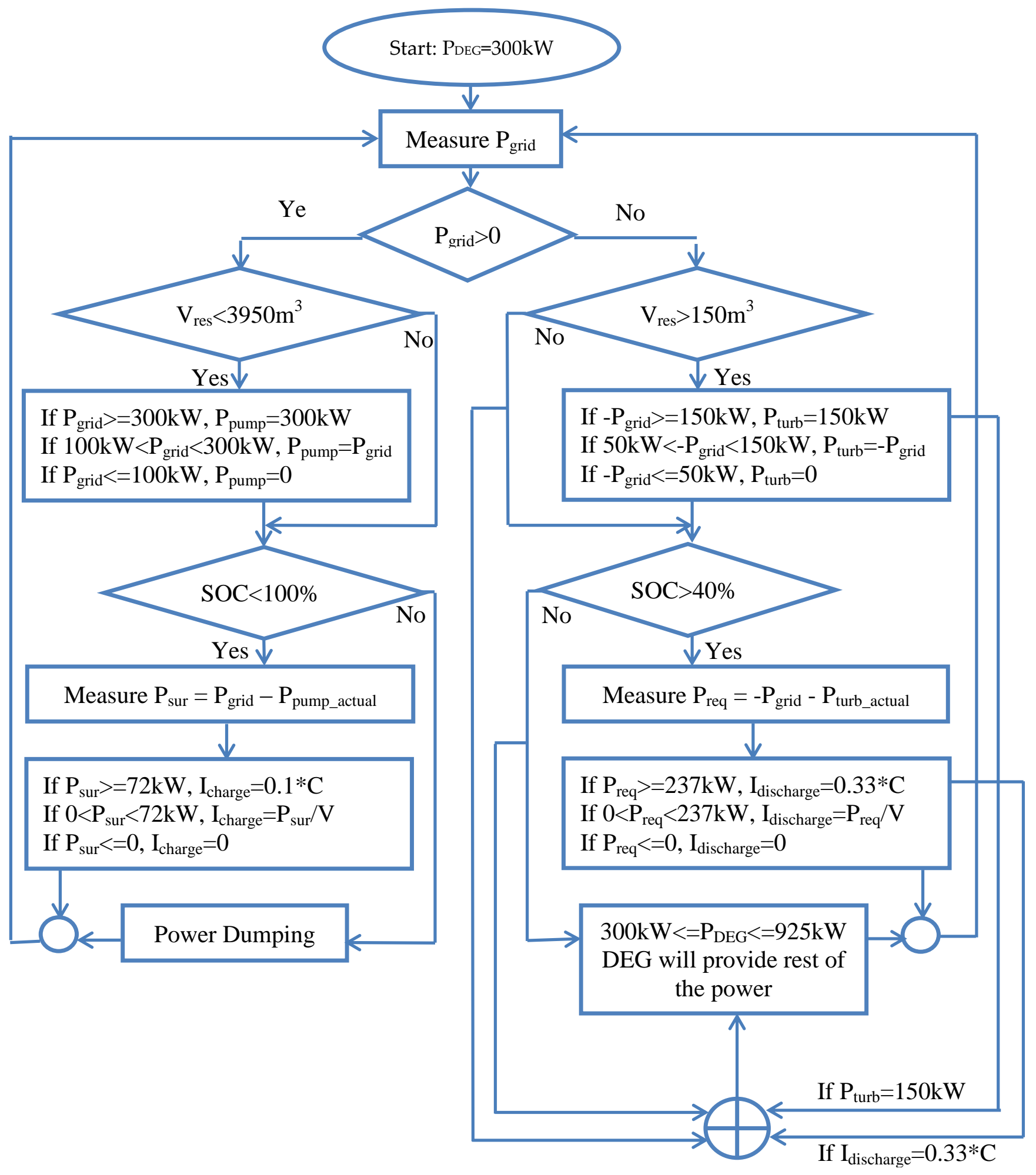




\section{Case 1: Low Load and Low Wind}

In Case 1, Low load and low wind speed have been used as inputs to the dynamic model and system outputs are observed.

From FIG. 6 to FIG. 10 it can be observed that in the first 30000 s load was very low so $\mathrm{CP}$ and $\mathrm{BB}$ charger worked to store the excess energy. From 30000s to 50000s load was increasing and PWT and BB delivered the necessary power. After 50000s reservoir is empty so DEG takes control and supply a maximum of $450 \mathrm{~kW}$ for some time. System frequency remains almost stable that day. A sudden frequency dip of $1.3 \mathrm{~Hz}$ is observed in FIG. 10 when load is increasing rapidly after $\mathrm{t}=30000$ s and $\mathrm{PWT}$ respond slowly. Such

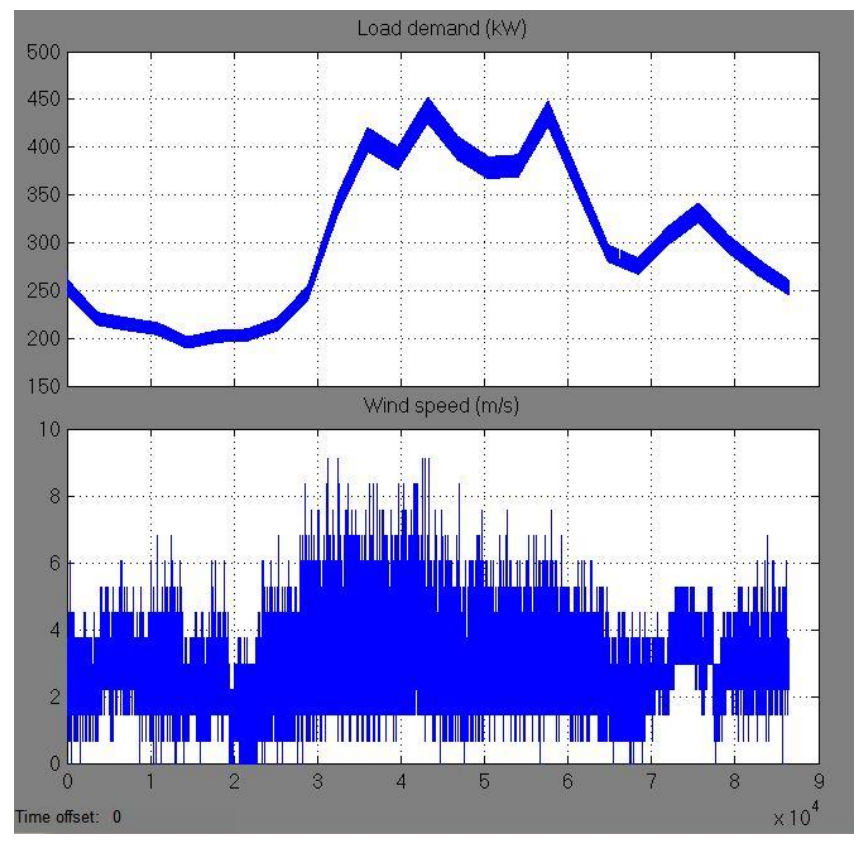

FIG. 6 LOAD DEMAND (kW) AND WIND SPEED (m/s) DATA FOR THE CASE 1

a frequency dip is acceptable in remote hybrid power systems. This case study indicates that the developed model and supervisory controller is capable of correctly simulating the hybrid power system. The transients observed in these figures are not instantaneous rather slow variations. The $x$-axes cover a whole day simulation (86400s) so these spikes are basically steady variations lasting minutes. In FIG. 11, a zoomed result from 57700 s to 57800 s has been shown.

\section{Case 2: Low Load and High Wind}

In case 2, a low load and high wind speed have been used in the dynamic model to observe the system outputs and responses. FIG. 12 shows the selected data. Daily load cycle and random variation is shown in the top section of FIG. 12. From FIG. 13 to FIG. 16 it can be

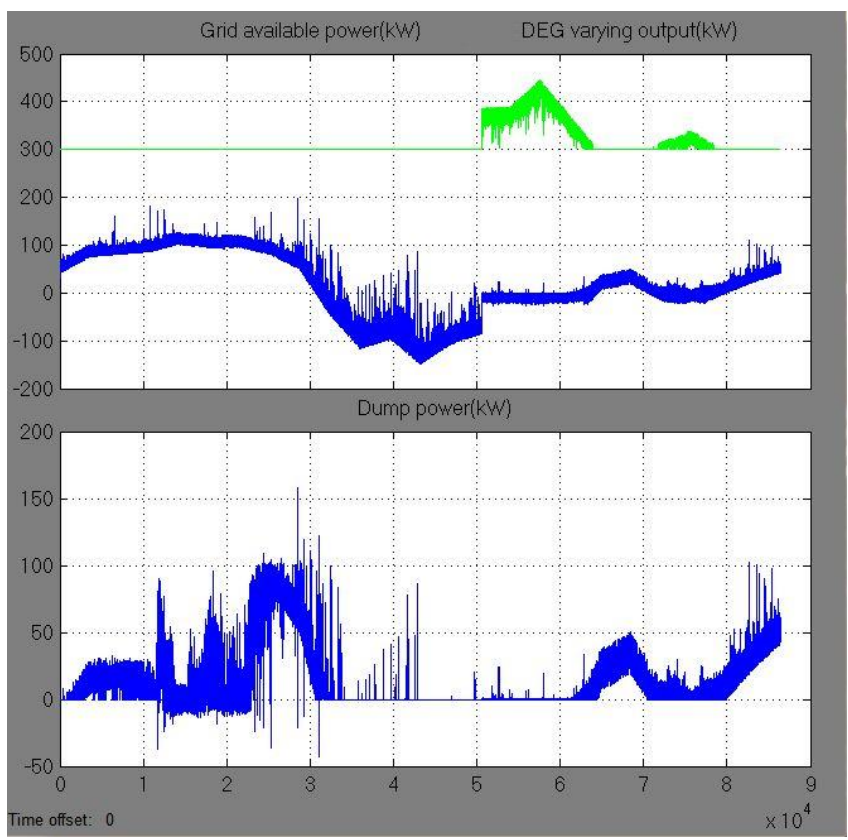

FIG. 7 IN TOP FIGURE, THE GRID AVAILABLE POWER $(\mathrm{kW})$ AND DEG VARYING OUTPUT $(\mathrm{kW}$ ) (WITH A MINIMUM 300kW

VALUE) IS SHOWN AND IN THE LOWER FIGURE DUMP POWER (kW) IS SHOWN FOR THE CASE 1

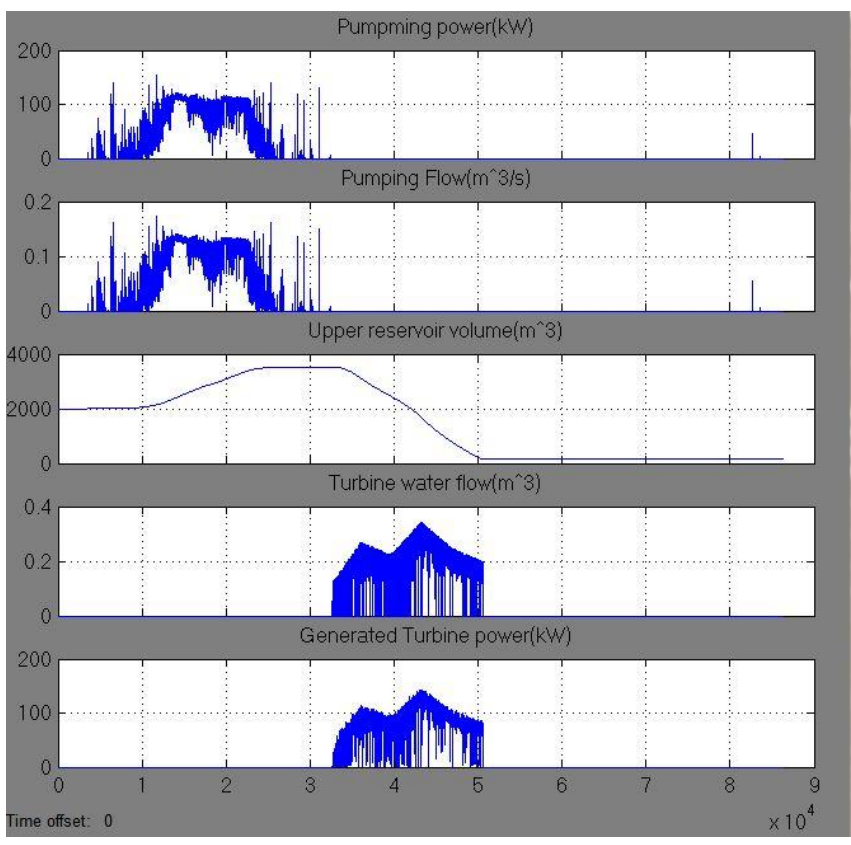

FIG. 8 PUMP POWER CONSUMPTION (kW), PUMP WATER FLOW $\left(\mathrm{m}^{3} / \mathrm{s}\right)$, THE UPPER RESERVOIR WATER VOLUME $\left(\mathrm{m}^{3}\right)$, TURBINE WATER FLOW RATE $\left(\mathrm{m}^{3} / \mathrm{s}\right)$ AND THE TURBINE GENERATED POWER $(\mathrm{kW})$ FOR THE CASE 1

observed that as wind is high and load is low, the water reservoir and $\mathrm{BB}$ become fully charged in the first 8000 s and 10000s respectively. After that all the excess power goes to the dump load. The maximum power dissipation in the dump load is $800 \mathrm{~kW}$. System frequency is totally stable for all time as it is maintained by the diesel. These results also show that the developed model is capable of correctly simulating 


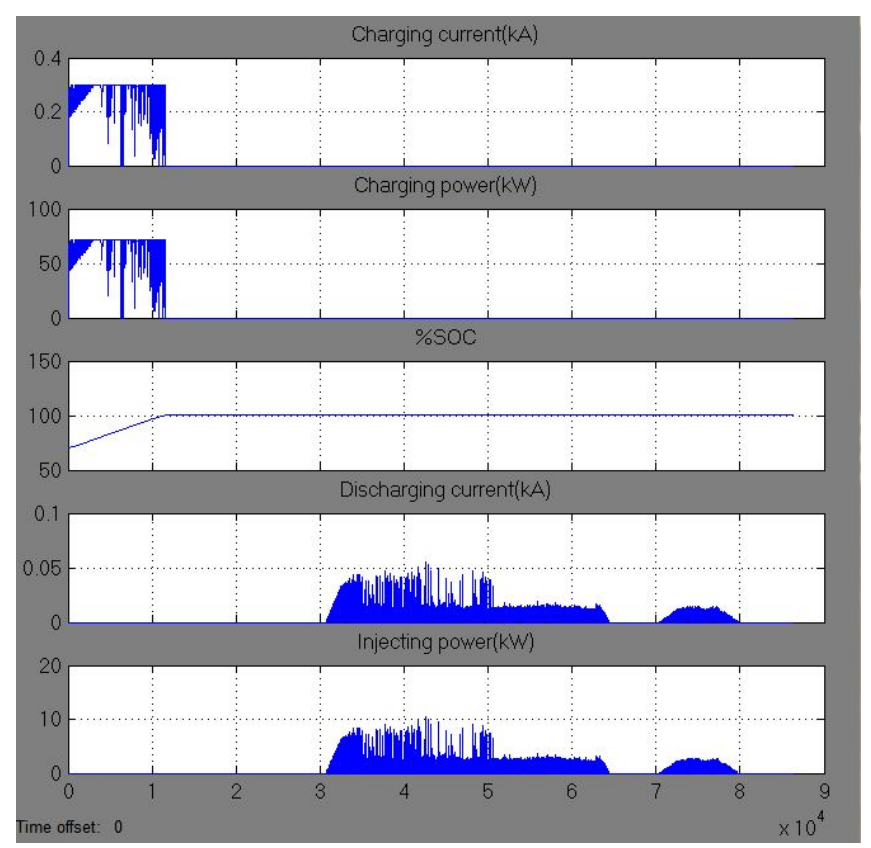

FIG. 9 BB CHARGING CURRENT (kA), CHARGING POWER (kW), PERCENTAGE OF STATE OF CHARGE, DISCHARGING CURRENT (kA) AND THE POWER TO THE GRID (kW) DUE TO THE DISCHARGING OF THE BATTERY ARE SHOWN FOR THE CASE 1

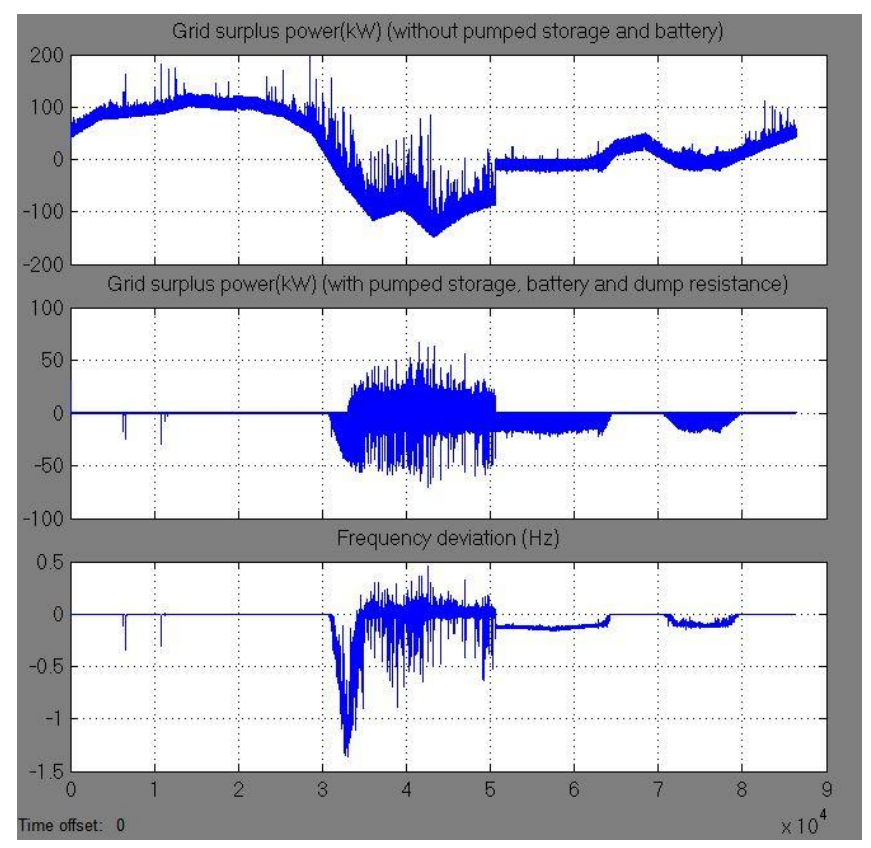

FIG. 10 GRID SURPLUS POWER (kW) WITH AND WITHOUT PUMPED STORAGE, BATTERY AND DUMP LOAD AND THE RESULTANT FREQUENCY DEVIATION FOR THE CASE 1

the complex Ramea hybrid power system.

\section{Case 3: High Load and Low Wind}

In case 3, high load and low wind speed have been used as inputs to the dynamic model to observe the outputs and system responses. Selected one day load data and wind speed are shown in FIG. 17 below.

From FIG. 17 to FIG. 21 it has been observed that in first a

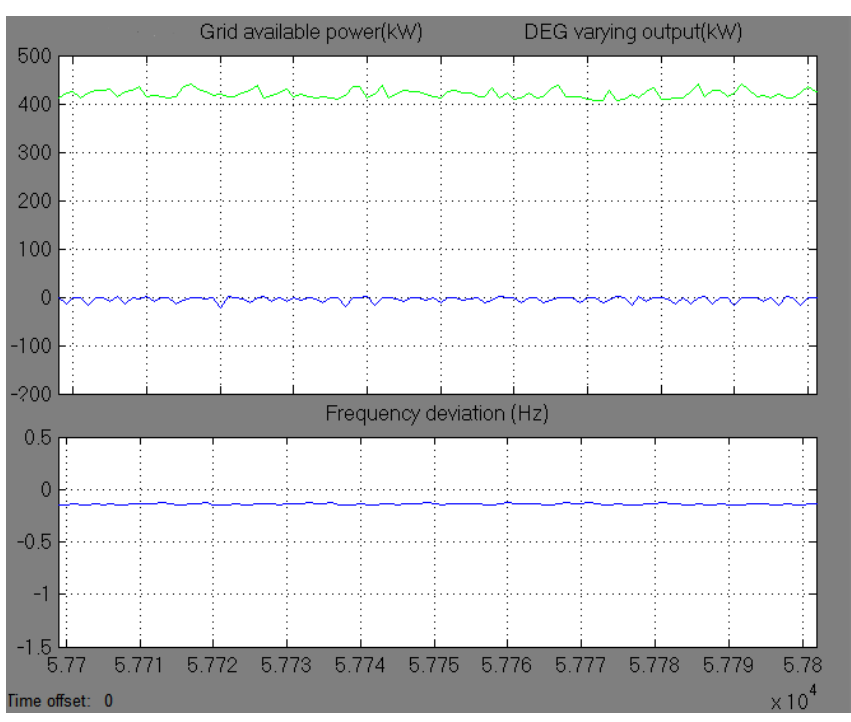

FIG. 11 SIMULATION RESULT HAS BEEN ZOOMED FROM 57700s TO 57800s TO SHOW THE TRANSIENTS. IN TOP FIGURE, THE GRID AVAILABLE POWER (kW) AND DEG VARYING OUTPUT $(\mathrm{kW})$ IS SHOWN AND IN THE LOWER FIGURE THE RESULTANT FREQUENCY DEVIATION IS SHOWN FOR THE CASE 1

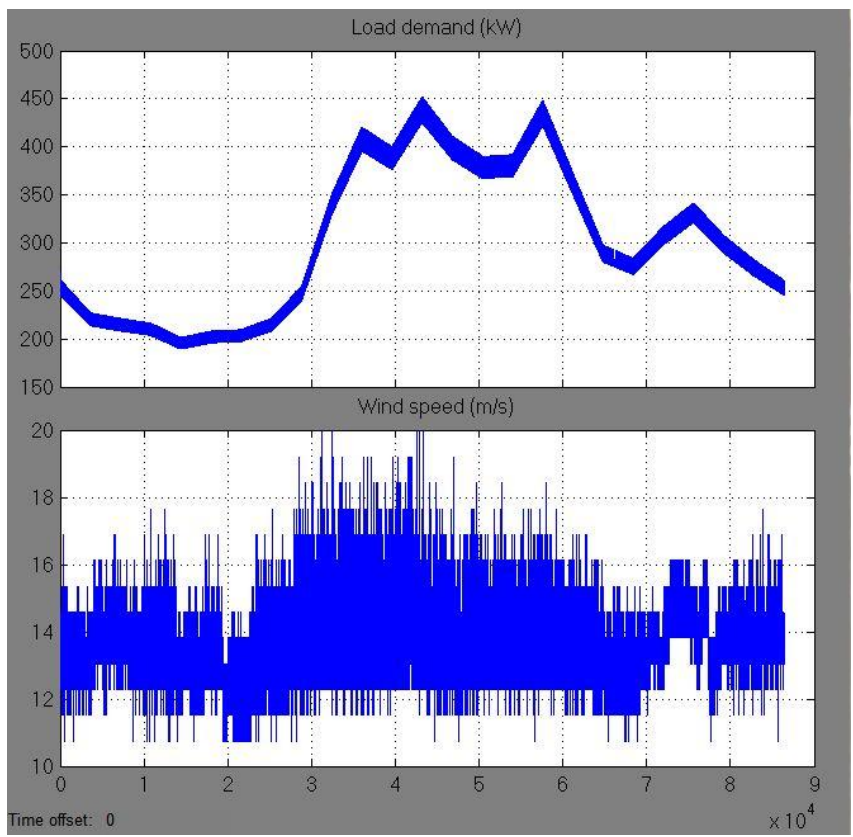

FIG. 12 LOAD DEMAND (kW) AND WIND SPEED (m/s) DATA FOR CASE 2

5500s reservoir becomes empty and by 10000s BB almost discharged. This is because load is very high and WT are not delivering enough power due to very low wind speed. DEG delivers the required amount No power dumping happened in this case. System frequency remains quite stable though two frequency dips of $0.6 \mathrm{~Hz}$ and $0.9 \mathrm{~Hz}$ are observed when load suddenly dips around 40000s and 60000s. Such small frequency dips are considered acceptable for remote hybrid power system. 


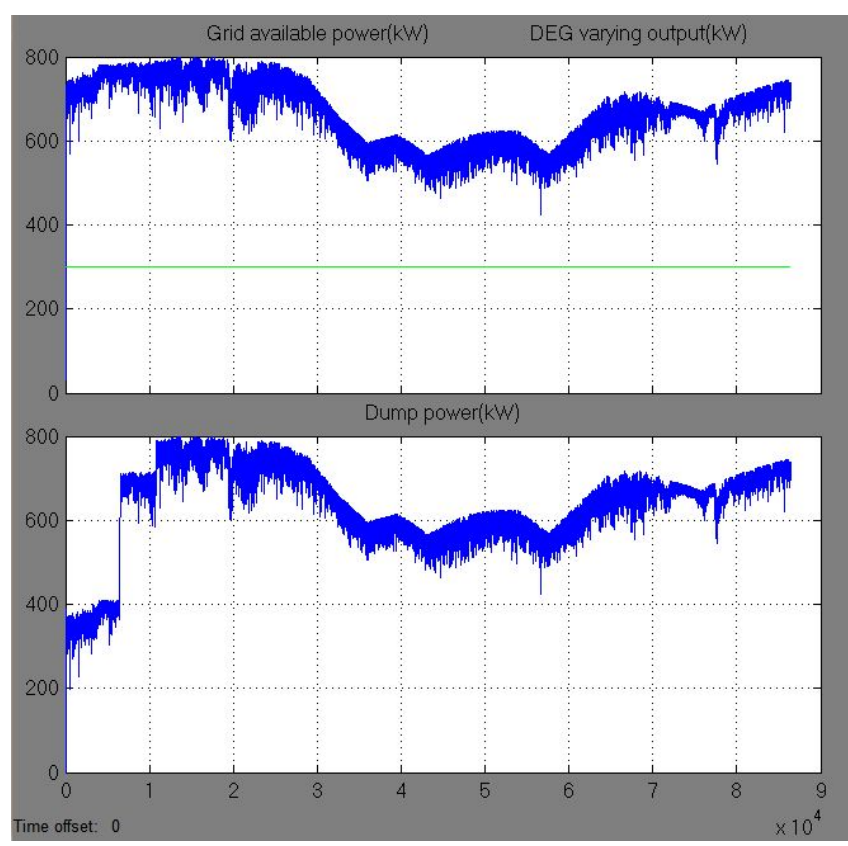

FIG. 13 IN THE TOP PART, GRID AVAILABLE POWER ( $\mathrm{kW}$ ) AND DEG OUTPUT (kW) (WITH FLAT 300kW VALUE) ARE SHOWN AND IN THE LOWER PART DUMP POWER (kW) IS SHOWN FOR THE CASE 2

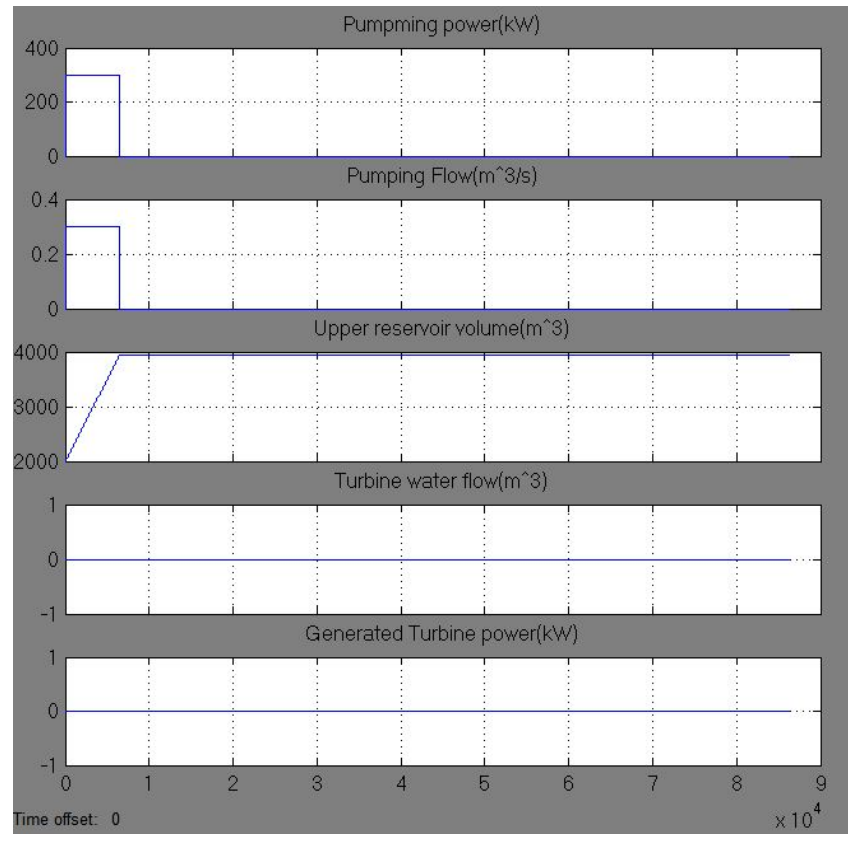

FIG. 14 PUMPING POWER (kW), PUMPING WATER FLOW RATE $\left(\mathrm{m}^{3} / \mathrm{s}\right)$, UPPER RESERVOIR WATER VOLUME $\left(\mathrm{m}^{3}\right)$, TURBINE WATER FLOW $\left(\mathrm{m}^{3} / \mathrm{s}\right)$ AND TURBINE GENERATED POWER $(\mathrm{kW})$ FOR THE CASE 2

\section{Case 4: High Load and High Wind}

For case 4, high load and high wind speed have been used as inputs to the dynamic model and observe the outputs and system responses. FIG. 22 shows the selected load and wind speed data for the case 4 . The system simulation results are shown in the FIG. 23 to FIG. 26 below. From FIG. 22 to FIG. 26 it has been observed that in the first 7000s reservoir becomes full

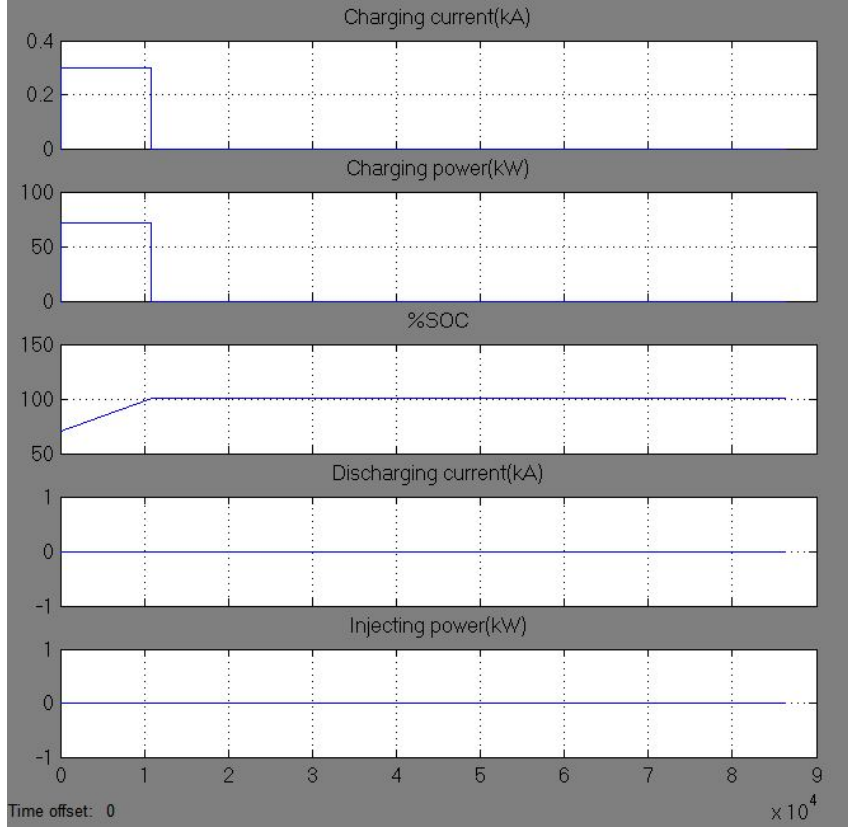

FIG. 15 BB CHARGING CURRENT (kA), CHARGING POWER (kW), PERCENTAGE OF STATE OF CHARGE, DISCHARGING CURRENT (kA) AND THEPOWER INJECTED TO THE GRID (kW) DUE TO THE DISCHARGING OF THE BATTERY ARE SHOWN ABOVE FOR THE CASE 2

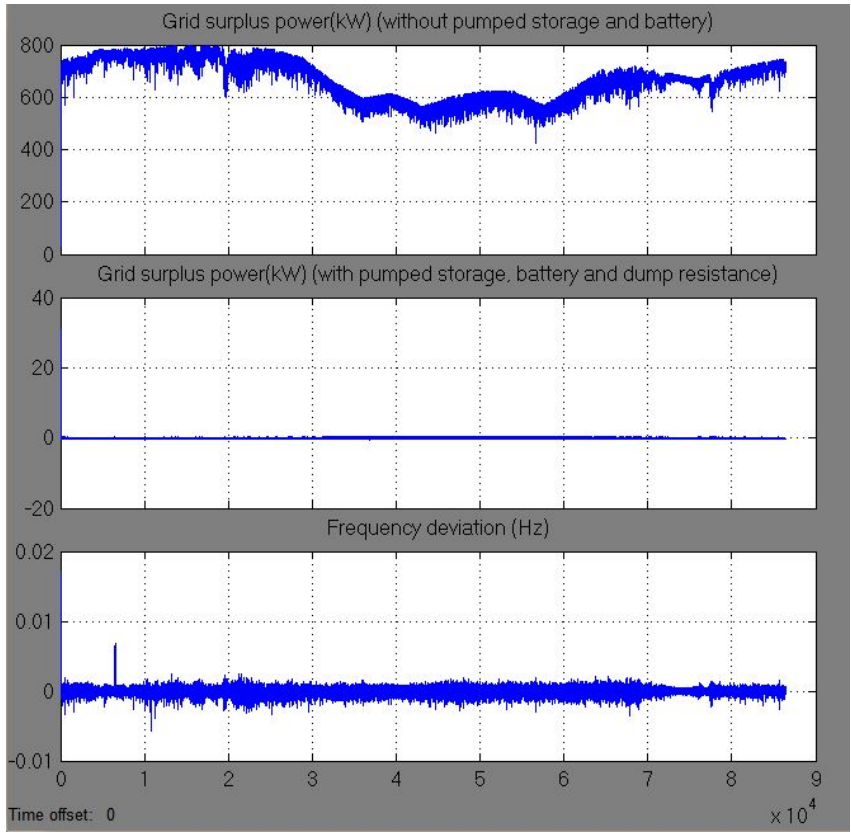

FIG. 16 GRID SURPLUS POWER (kW) WITH AND WITHOUT PUMPED STORAGE, BATTERY AND DUMP LOAD AND THE RESULTANT FREQUENCY DEVIATION ARE SHOWN ABOVE FOR THE CASE 2

and by 12000 s BB is showing $100 \%$ SOC. As wind is very high WTs are generating enough power to the system so DEG delivers only $300 \mathrm{~kW}$ and maintains the system stability. Remaining excess power is being dumped depending on the load changes. System frequency is stable for the whole time. One frequency dip of $0.4 \mathrm{~Hz}$ is observed at $65000 \mathrm{~s}$. This happens when hydro generation turns on for a while. 


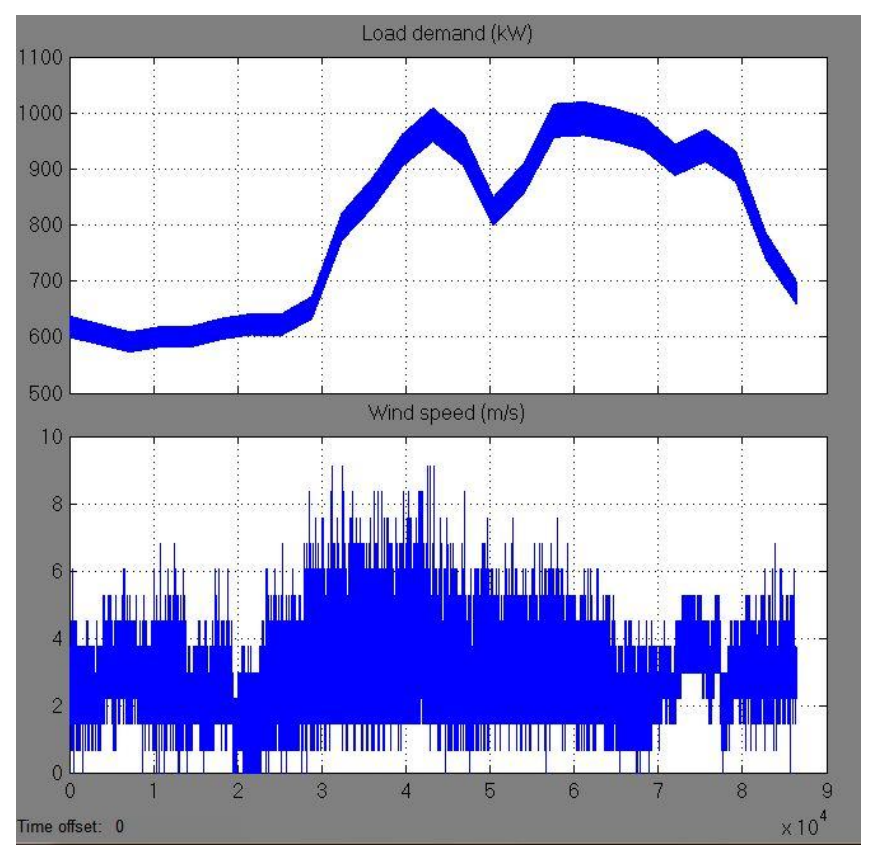

FIG. 17 LOAD DEMAND (kW) AND WIND SPEED (m/s) DATA FOR THE CASE 3

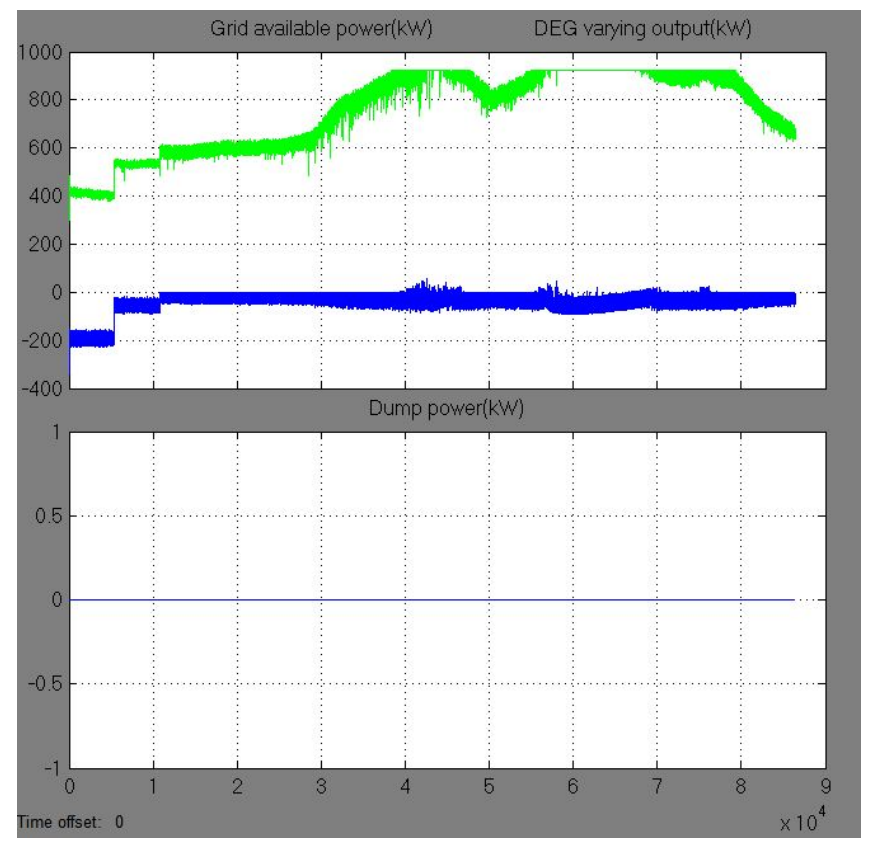

FIG. 18 IN TOP FIGURE, GRID AVAILABLE POWER (kW) AND DEG VARYING OUTPUT (kW) (FROM 400kW TO 925kW) ARE SHOWN AND IN THE BOTTOM PART DUMP POWER (kW) IS SHOWN FOR THE CASE 3

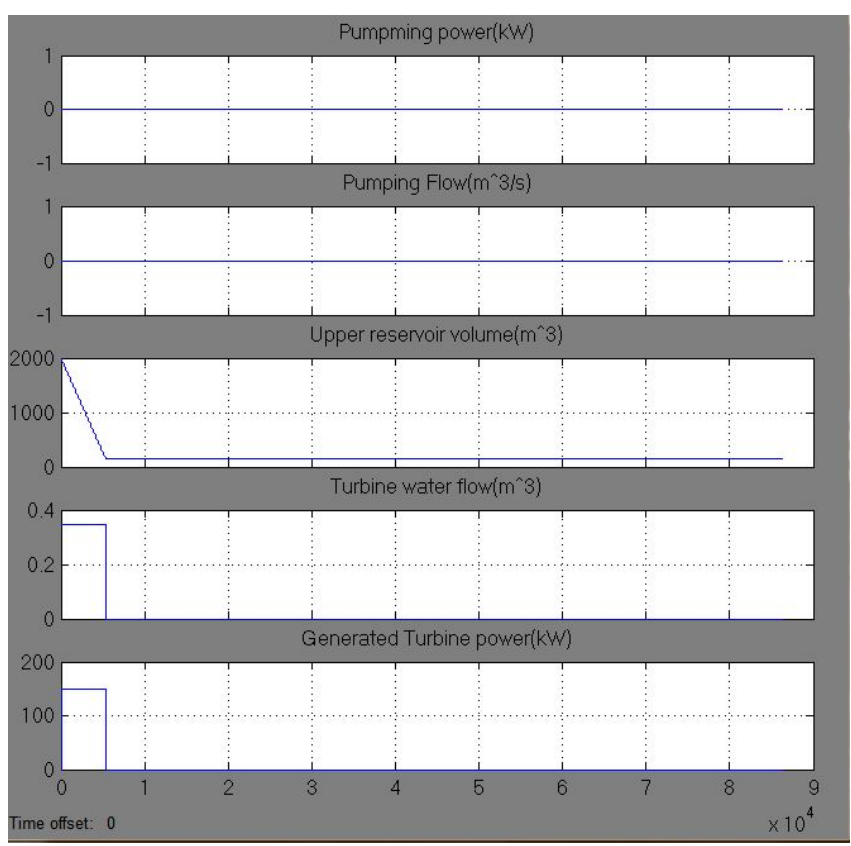

FIG. 19 PUMPING POWER (kW), PUMPING WATER FLOW $\left(\mathrm{m}^{3} / \mathrm{s}\right)$ UPPER RESERVOIR WATER VOLUME $\left(\mathrm{m}^{3}\right)$, TURBINE WATER FLOW $\left(\mathrm{m}^{3} / \mathrm{s}\right)$ AND TURBINE GENERATED POWER $(\mathrm{kW})$ ARE SHOWN FOR THE CASE 3

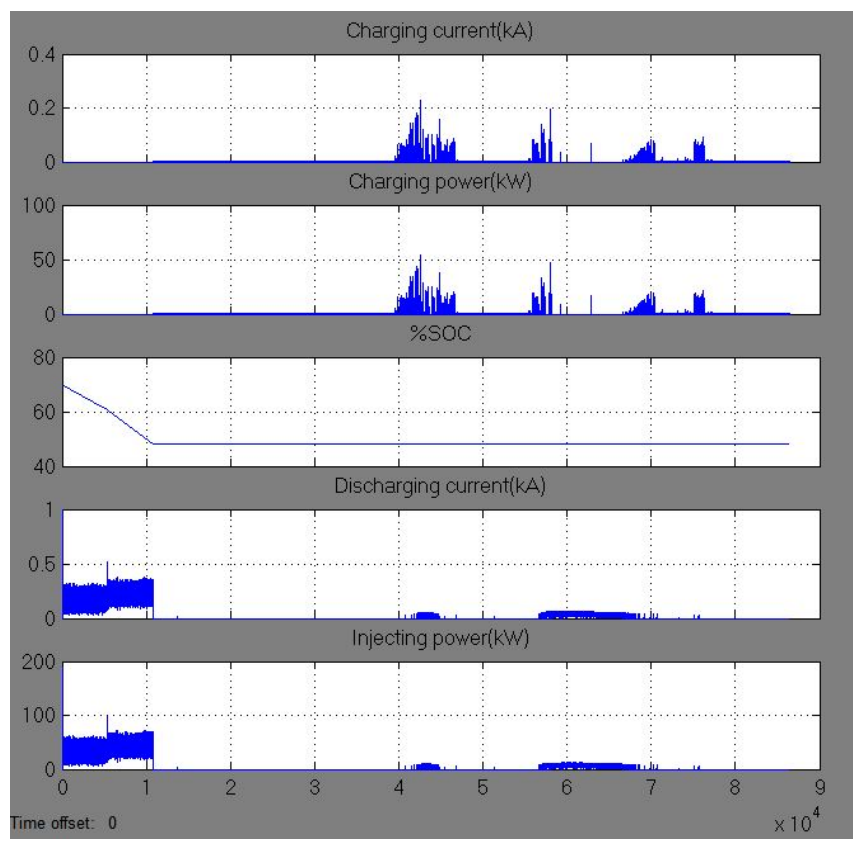

FIG. 20 CHARGING CURRENT (kA), CHARGING POWER (kW) PERCENTAGE OF STATE OF CHARGE, DISCHARGING CURRENT (kA) AND INJECTED POWER TO THE GRID (kW) DUE TO THE DISCHARGING OF THE BATTERY ARE FOR THE CASE 


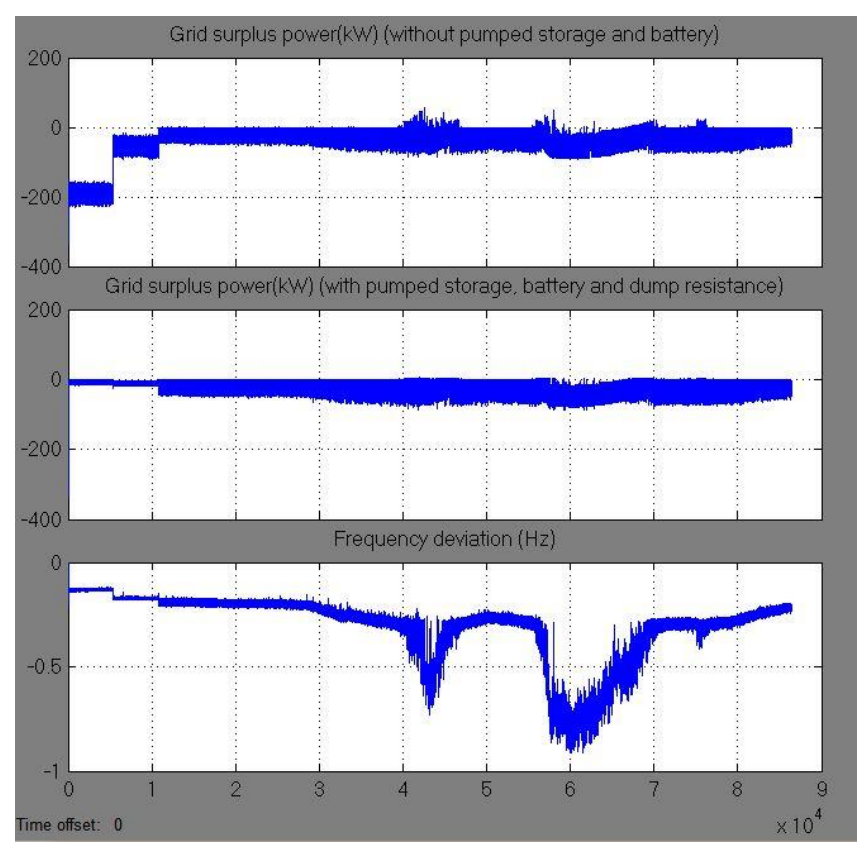

FIG. 21 GRID SURPLUS POWER $(\mathrm{kW})$ WITH AND WITHOUT PUMPED STORAGE, BATTERY AND DUMP LOAD AND THE RESULTANT SYSTEM FREQUENCY DEVIATION FOR THE CASE 3

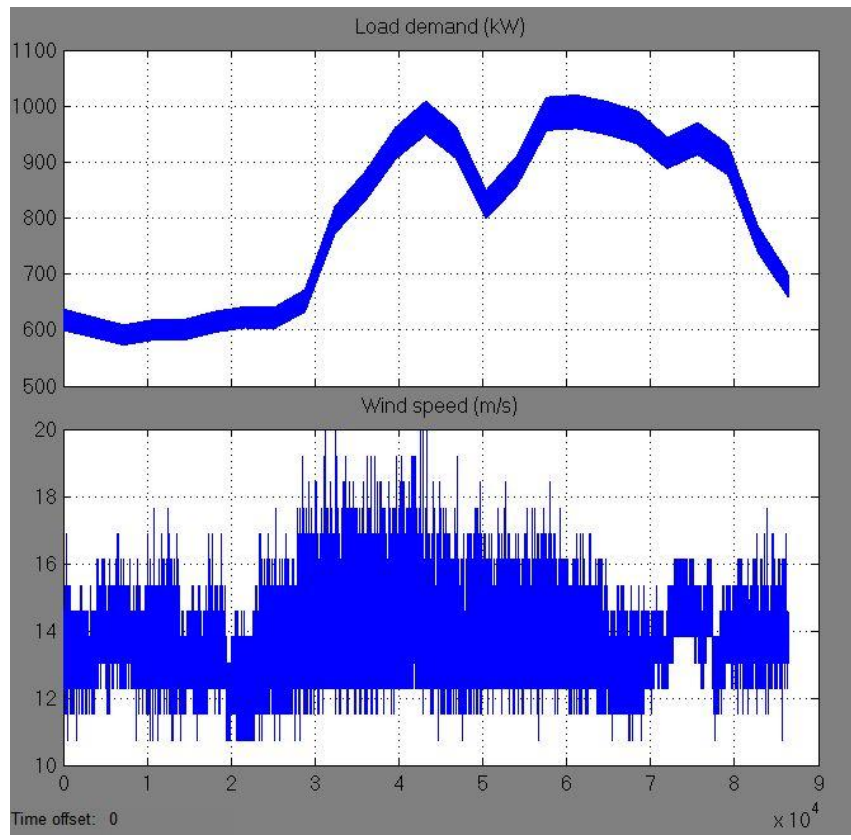

FIG. 22 LOAD DEMAND (kW) AND WIND SPEED (m/s) DATA FOR THE CASE 4

Case 5: Abrupt Change of Load While Wind Speed Is Steady in the Midrange

For this case study a simple step change in the load is assumed. This case study is done to observe the system dynamics in case of a change in the load. From FIG. 26 to FIG. 31 it has been found that PWT supplies a maximum of $150 \mathrm{~kW}$ power for the whole time and DEG delivers the excess required amount from 200s to

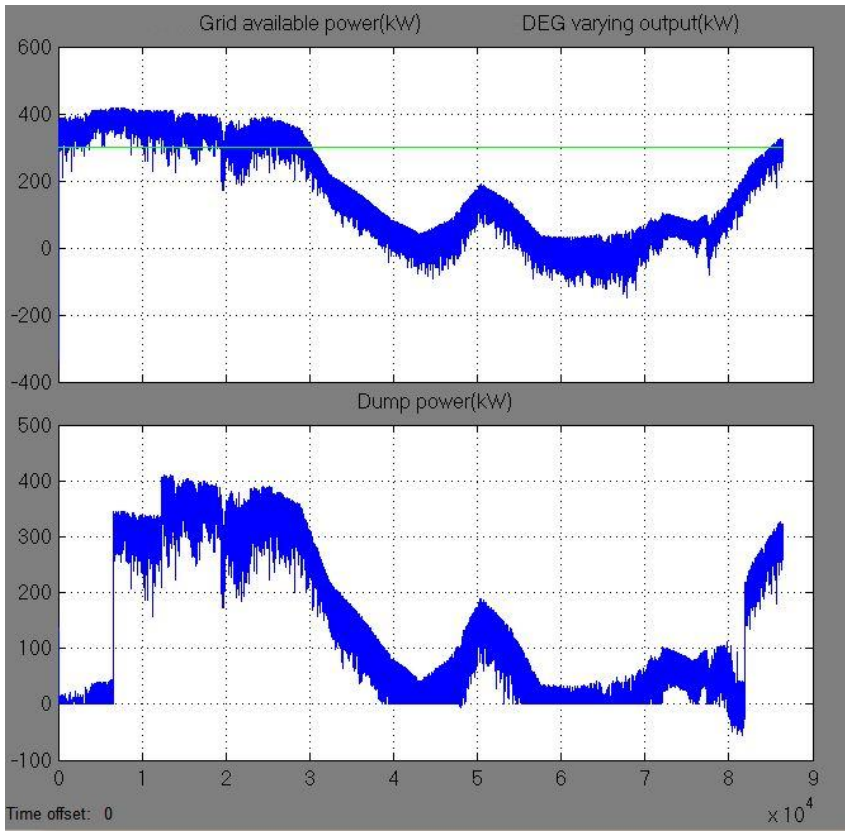

FIG. 23 IN TOP FIGURE GRID AVAILABLE POWER $(\mathrm{kW})$ AND DEG OUTPUT $(\mathrm{kW})$ (FLAT 300kW VALUE) ARE SHOWN AND IN THE LOWER PART DUMP POWER (kW) IS SHOWN FOR THE CASE 4

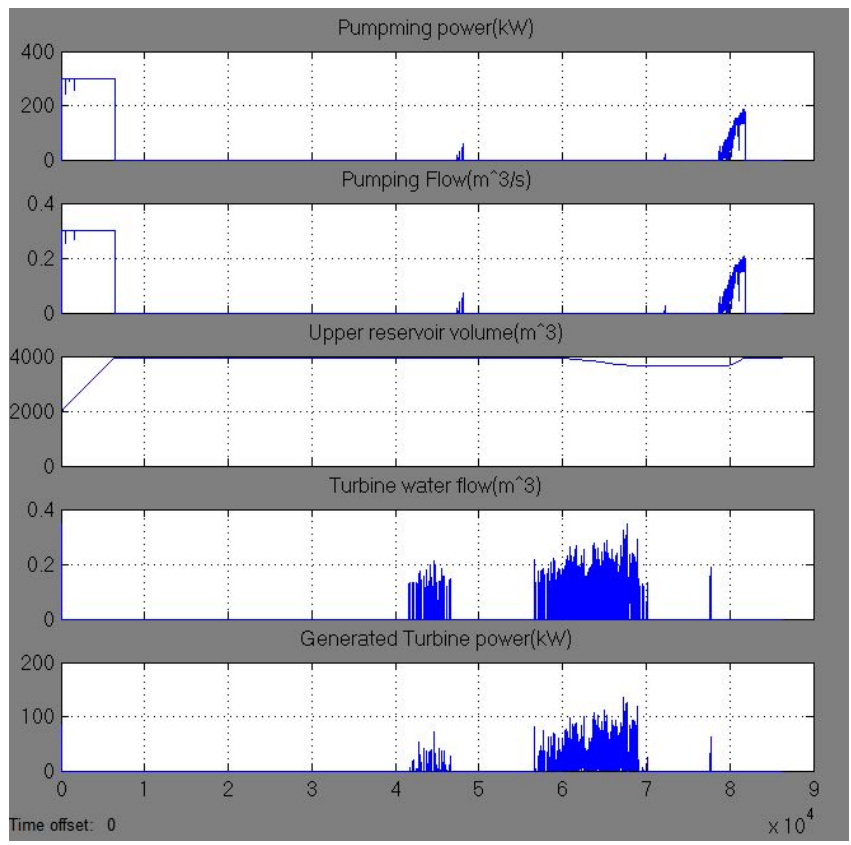

FIG. 24 PUMPING POWER (kW), PUMPING WATER FLOW $\left(\mathrm{m}^{3} / \mathrm{s}\right)$, UPPER RESERVOIR WATER VOLUME $\left(\mathrm{m}^{3}\right)$, TURBINE WATER FLOW $\left(\mathrm{m}^{3} / \mathrm{s}\right)$ AND TURBINE GENERATED POWER $(\mathrm{kW})$ FOR THE CASE 4 ARE SHOWN ABOVE

700s. No water pumping and no power dumping occur. Such sudden load change of $200 \mathrm{~kW}$ leads to a frequency fluctuation of $0.2 \mathrm{~Hz}$ that dies down in $40 \mathrm{~s}$. System is capable of maintaining an almost stable frequency in such rare event. 


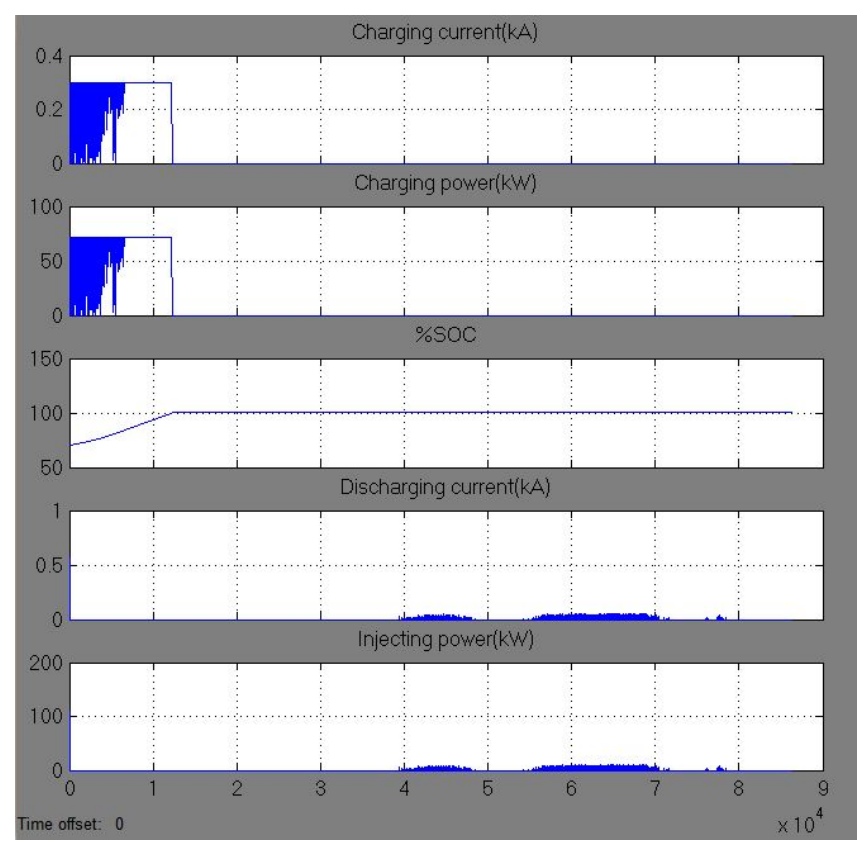

FIG. 25 CHARGING CURRENT (kA), CHARGING POWER (kW), PERCENTAGE OF STATE OF CHARGE, DISCHARGING CURRENT (kA) AND THE POWER INJECTED TO THE GRID (kW) DUE TO THE DISCHARGING OF THE BATTERY ARE SHOWN ABOVE FOR THE CASE 4

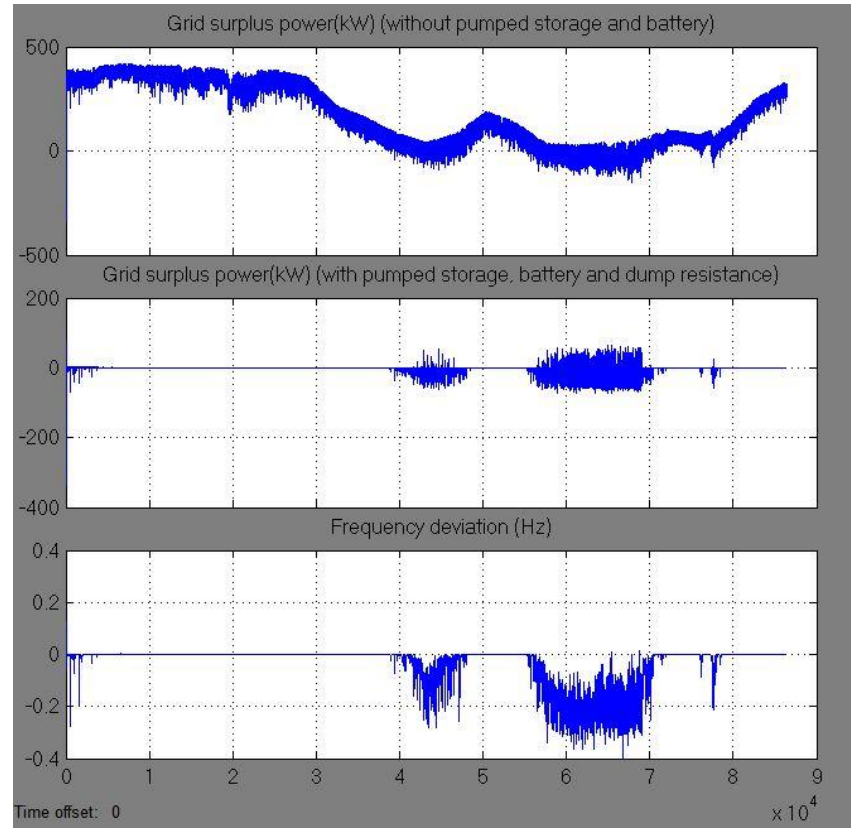

FIG. 26 GRID SURPLUS POWER (kW) WITH AND WITHOUT PUMPED STORAGE, BATTERY AND DUMP LOAD ARE SHOWN ABOVE. THE RESULTANT FREQUENCY DEVIATION IS ALSO PLOTTED FOR THE CASE 4

\section{Case 6: Load Is Steady in the Midrange and Wind Speed Is Changed Abruptly}

In this case study load is a constant while wind speed is increased and then decreased. The system inputs are shown in the FIG. 32. Simulation results are shown in FIG. 32 to FIG. 36.

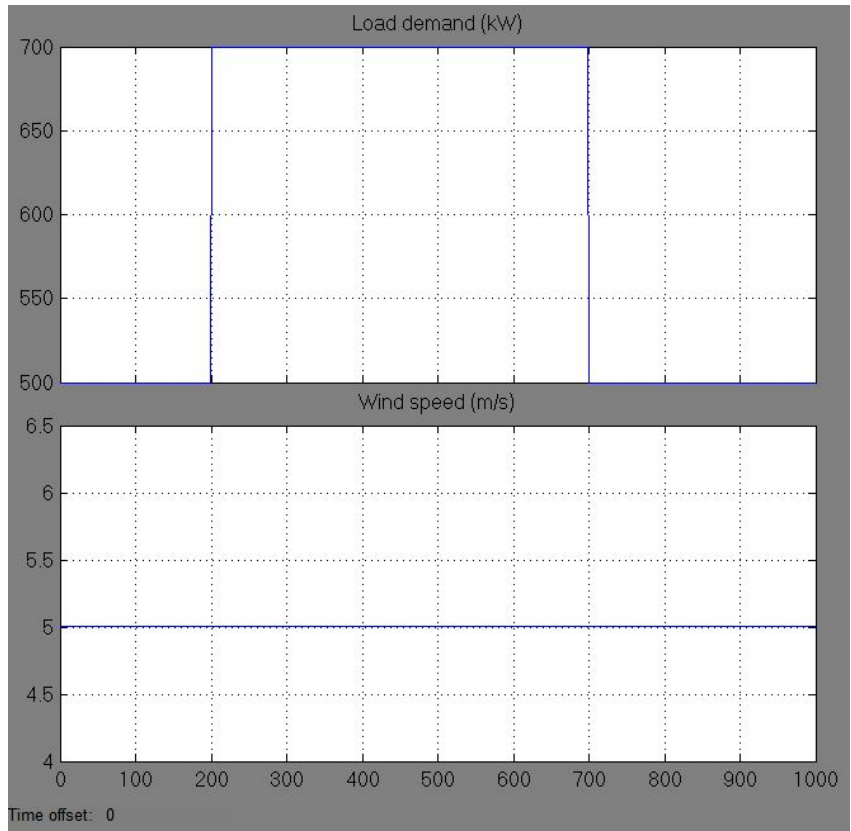

FIG. 27 LOAD DEMAND (kW) AND WIND SPEED (m/s) DATA FOR THE CASE 5

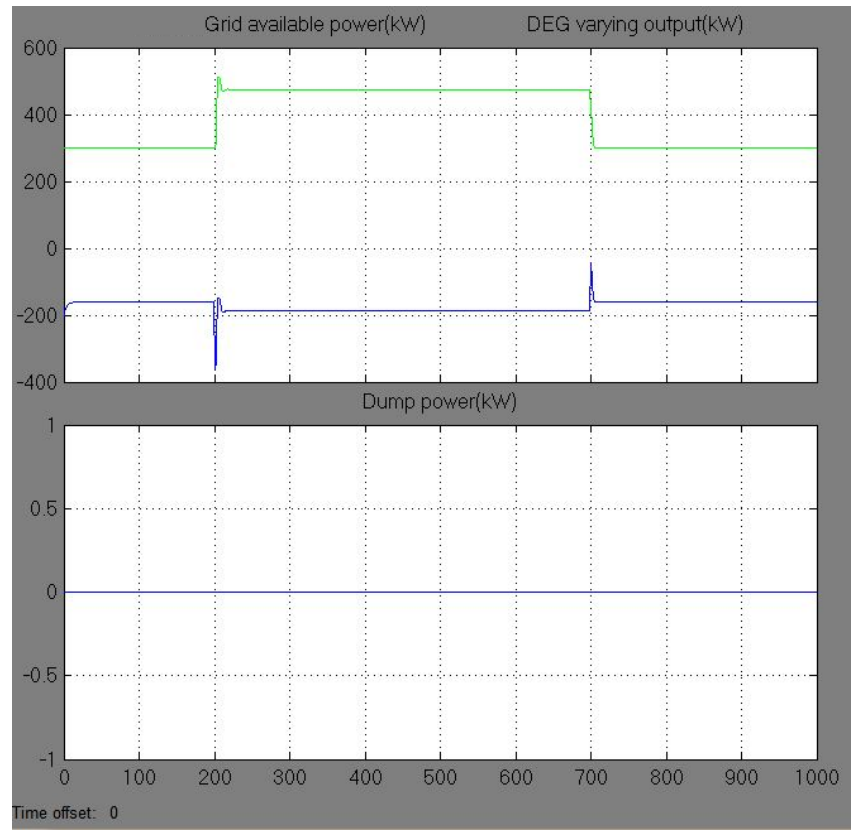

FIG. 28 IN TOP PART, GRID AVAILABLE POWER (kW) AND DEG VARYING OUTPUT $(\mathrm{kW})$ (THAT CHANGES FROM 300kW TO $500 \mathrm{~kW}$ ) ARE SHOWN. IN THE LOWER PART DUMP LOAD POWER (kW) IS PLOTTED FOR THE CASE 5

From FIG. 31 to FIG. 36 it has been found that as wind speed increases the water pumping starts and operates of its maximum rating from $t=200 \mathrm{~s}$ to $700 \mathrm{~s}$. $\mathrm{BB}$ is charging too for a while. DEG is supplying $300 \mathrm{~kW}$ all time.

At 700 s a sudden $1.1 \mathrm{~Hz}$ system frequency dip is found when wind speed drops from to $8 \mathrm{~m} / \mathrm{s}$ from $11 \mathrm{~m} / \mathrm{s}$. Such a large dip may not be acceptable. But a sudden wind speed drop of $3 \mathrm{~m} / \mathrm{s}$ is impossible. This case study shows that the proposed supervisory controller 


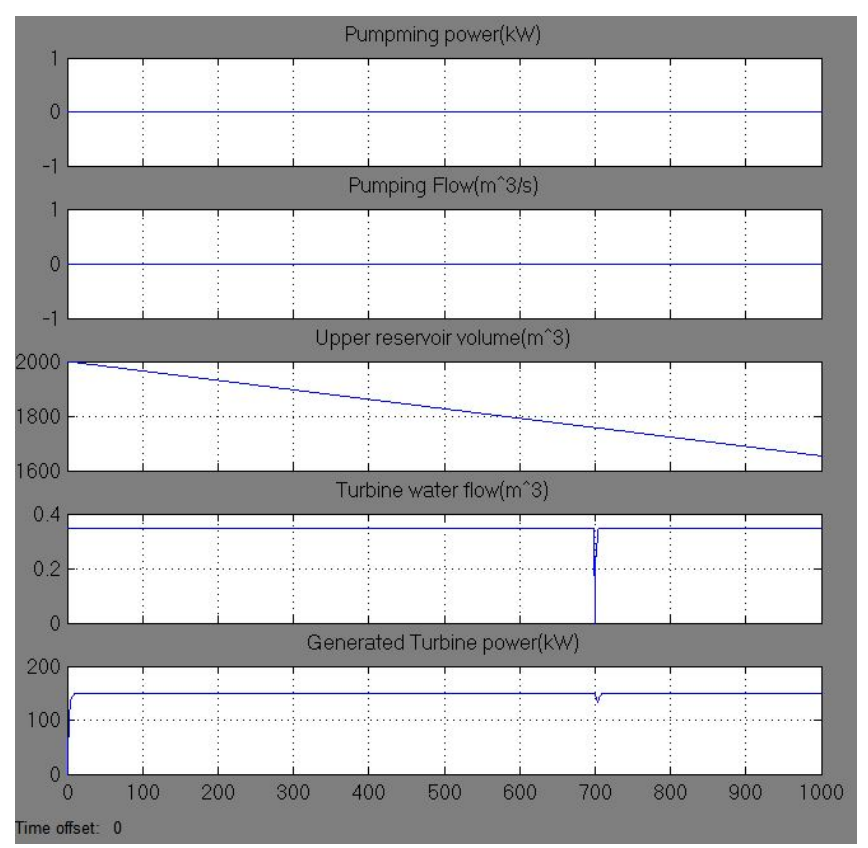

FIG. 29 PUMPING POWER (kW), PUMPING WATER FLOW $\left(\mathrm{m}^{3} / \mathrm{s}\right)$, UPPER RESERVOIR WATER VOLUME $\left(\mathrm{m}^{3}\right)$, TURBINE WATER FLOW $\left(\mathrm{m}^{3} / \mathrm{s}\right)$ AND TURBINE GENERATED POWER $(\mathrm{kW})$ ARE PLOTTED ABOVE FOR THE CASE 5

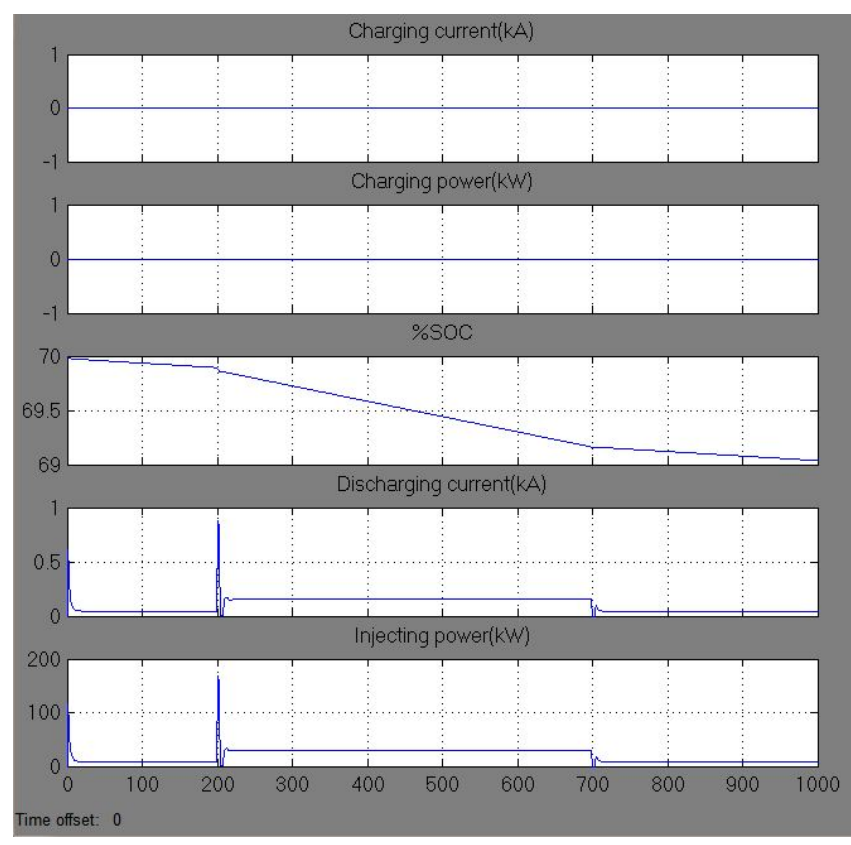

FIG. 30 BB CHARGING CURRENT (kA), CHARGING POWER $(\mathrm{kW})$, PERCENTAGE OF STATE OF CHARGE, DISCHARGING CURRENT (kA) AND INJECTING POWER TO THE GRID (kW) DUE TO THE DISCHARGING OF THE BATTERY ARE PLOTTED ABOVE FOR THE CASE 5

is capable of controlling the system in extreme conditions.

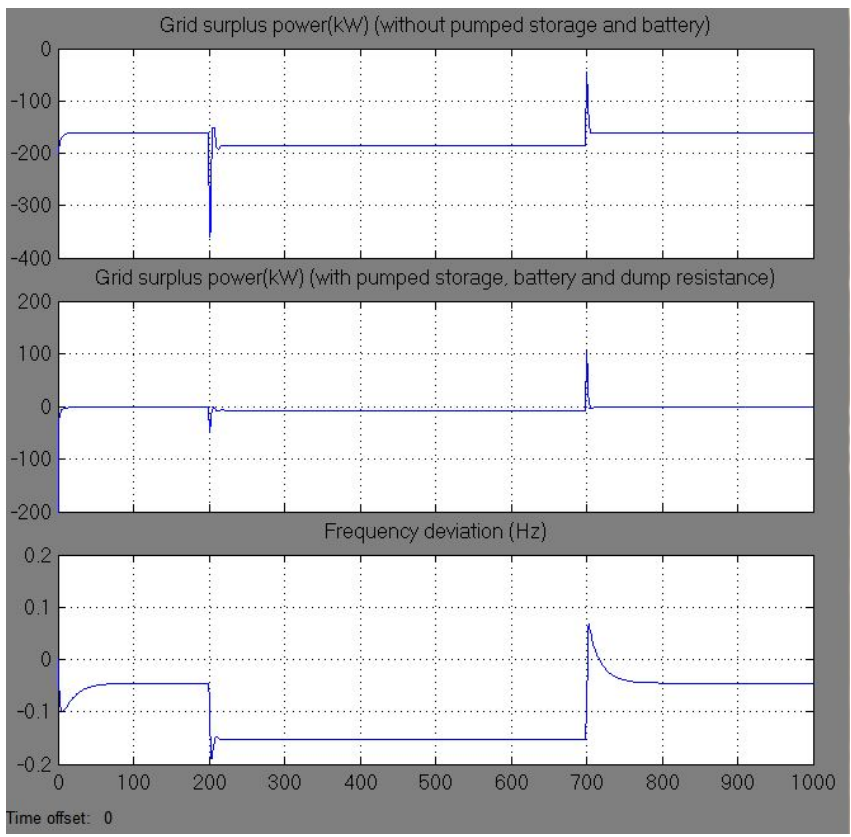

FIG. 31 THE GRID SURPLUS POWER (kW) WITH AND WITHOUT PUMPED STORAGE, BATTERY AND DUMP LOAD AND THE RESULTANT FREQUENCY DEVIATION FOR THE CASE 5

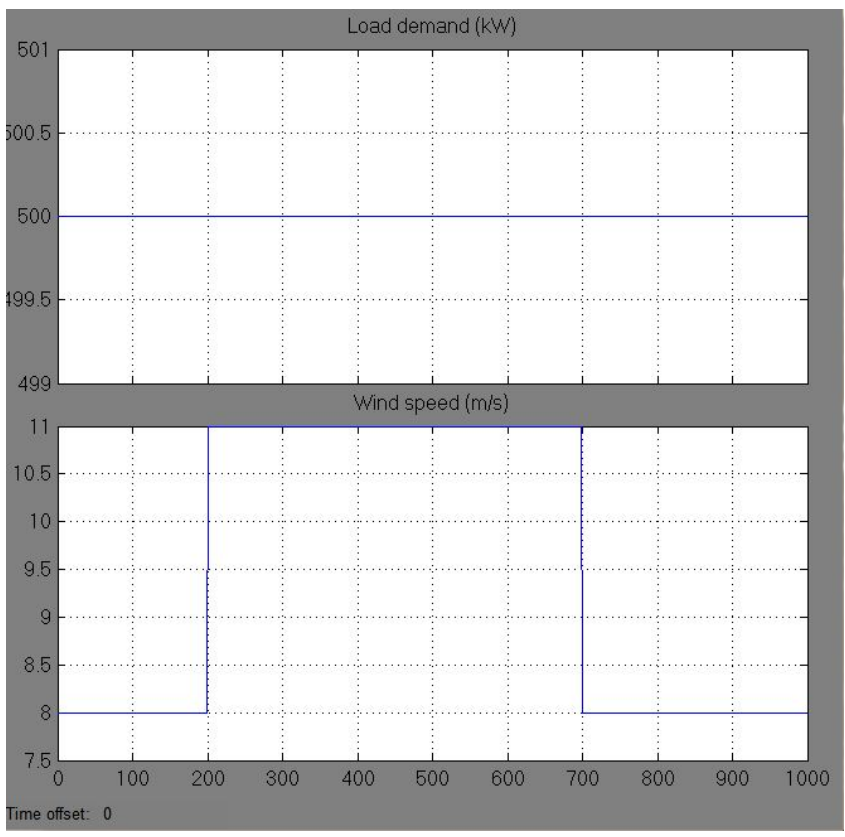

FIG. 32 LOAD DEMAND (kW) AND WIND SPEED (m/s) DATA FOR THE CASE 6

All above discussed 6 cases show almost steady system frequency for extreme conditions. These are extreme situations for the load demand and wind speed data in a year. Real situations may be much milder than above selected cases. 


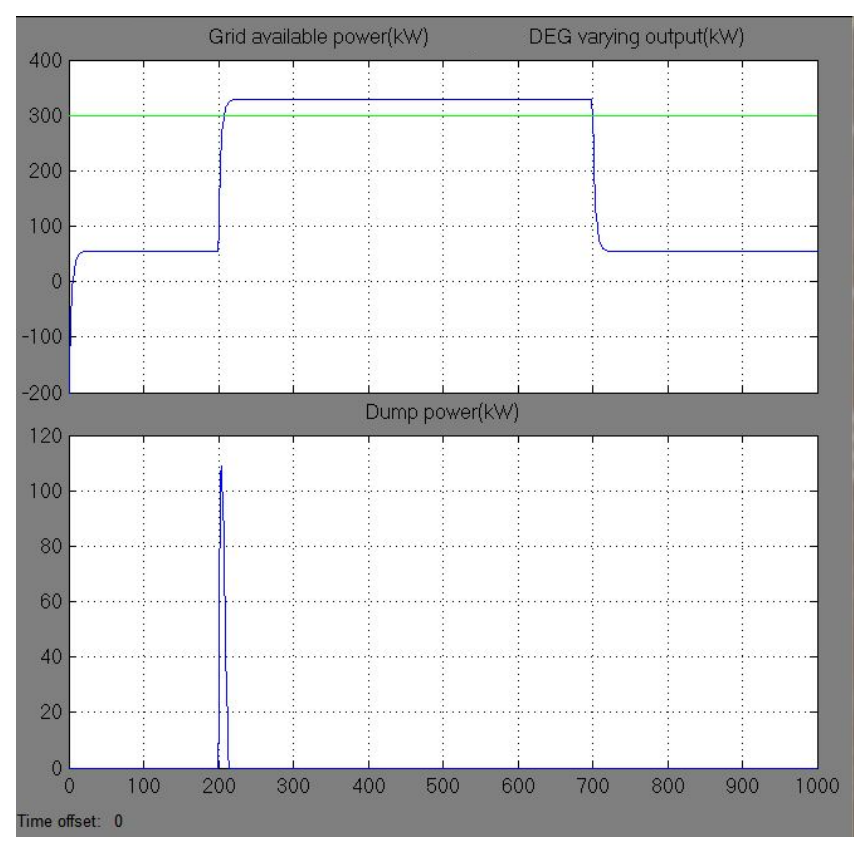

FIG. 33 IN THE TOP PART, GRID AVAILABLE POWER (kW) AND DEG VARYING OUTPUT (kW) (WITH A FLAT 300kW) AND IN BOTTOM PART DUMP POWER (kW) IS SHOWN FOR THE CASE 6

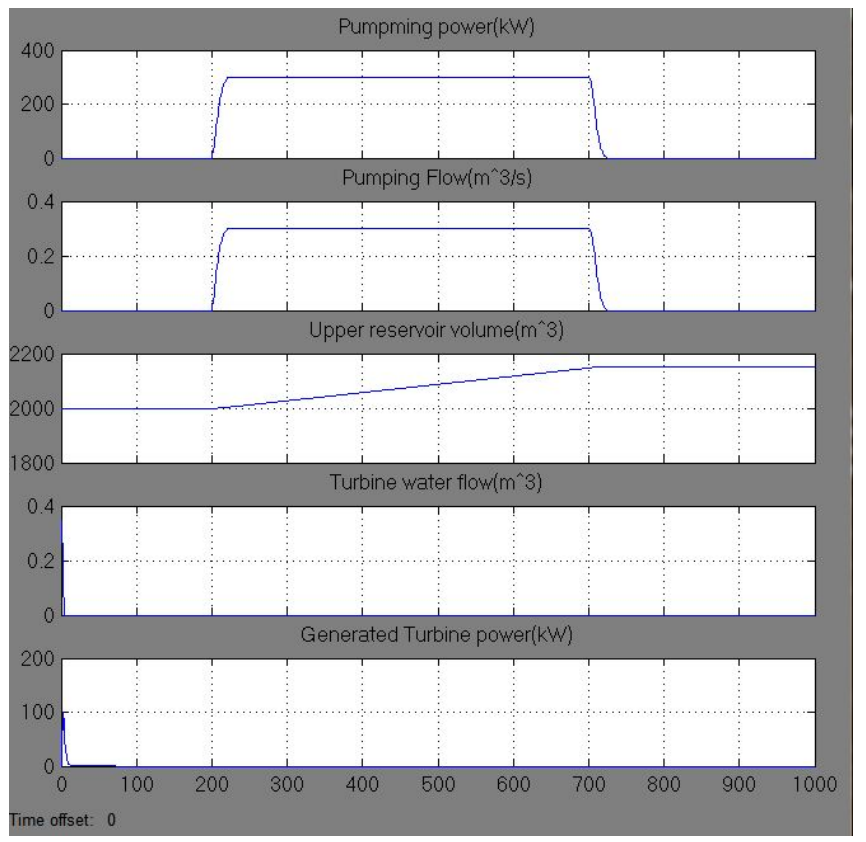

FIG. 34 PUMPING POWER (kW), PUMPING WATER FLOW $\left(\mathrm{m}^{3} / \mathrm{s}\right)$, UPPER RESERVOIR WATER VOLUME $\left(\mathrm{m}^{3}\right)$, TURBINE WATER FLOW $\left(\mathrm{m}^{3} / \mathrm{s}\right)$ AND TURBINE GENERATED POWER $(\mathrm{kW})$ ARE SHOWN ABOVE FOR THE CASE 6

\section{Conclusions}

This paper presented a dynamic simulation model and a supervisory controller for a remote hybrid power system with a proposed pumped hydro storage. From the simulation results, based on six possible extreme cases, it can be concluded a) a minimum of $300 \mathrm{~kW}$ operation of DEG permits higher penetration of wind

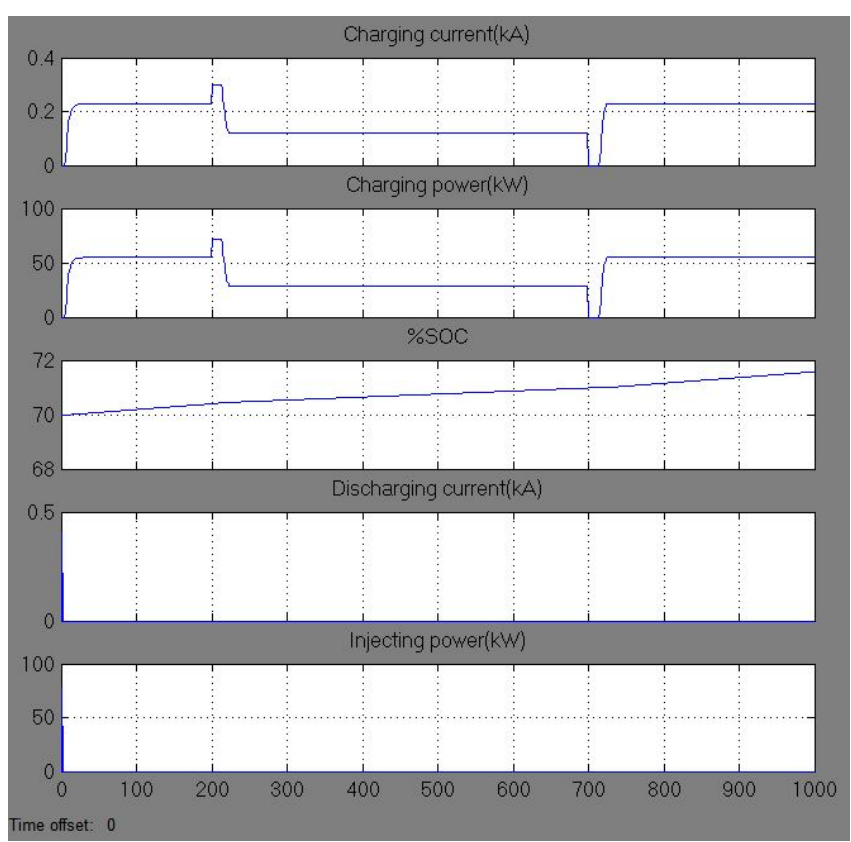

FIG. 35 CHARGING CURRENT (kA), CHARGING POWER (kW), PERCENTAGE OF STATE OF CHARGE, DISCHARGING CURRENT (kA) AND INJECTED POWER TO THE GRID (kW) DUE TO THE DISCHARGING OF THE BATTERY ARE PLOTTED ABOVE FOR THE CASE 6

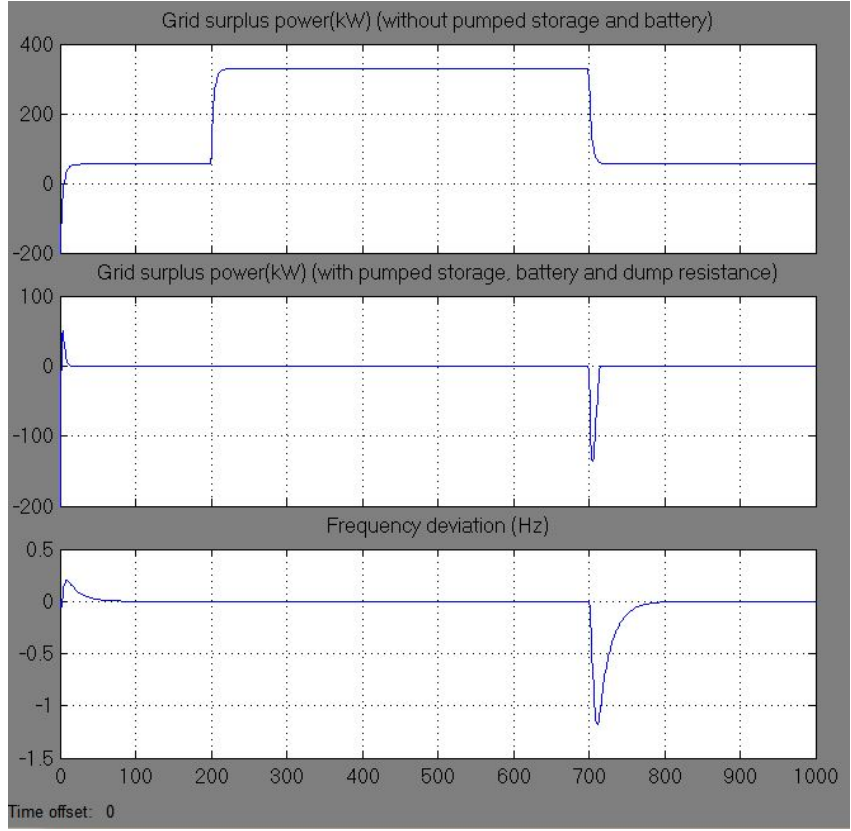

FIG. 36 GRID SURPLUS POWER (kW) WITH AND WITHOUT PUMPED STORAGE, BATTERY AND DUMP RESISTANCE AND THE RESULTANT FREQUENCY DEVIATION ARE SHOWN ABOVE FOR THE CASE 6

energy and leads to a low diesel consumption and maintains a fairly stable system frequency $b$ ) proposed dump load addition will prevent the system frequency spikes in high wind and make the system operation easier and results in less frequency deviations. Expected response of pump hydro system with battery storage is acceptable for a remote location like Remea 
Island. Simulation of the presented dynamic model with proposed PHS, BB and dump load is significantly fast. Using a $0.01 \mathrm{~s}$ time step, a day i.e. 86400s simulation takes about $30 \mathrm{~min}$ to complete on a computer with Intel Core2Duo $2.1 \mathrm{GHz}$ processor. The system model presented in this paper includes all real world characteristics curves, nonlinear efficiencies, losses and a supervisory controller. Moreover, this model can be used to check system stability and be modified easily for possible future extension to the hybrid power system. Wind data and load data of any day can be used with the model to determine the system expected response. This model allows us to simulate few months of operations of Ramea hybrid system and study parameters such as fuel consumption. Such a study is not possible in any commercially available software. Incorporating higher order complicated system components models in the blocks of this model can improve this model but that will considerably increase the simulation time. As a future work, system AC voltage analysis can be done to observe the voltage variations in the system.

\section{ACKNOWLEDGMENT}

Authors thank The Wind Energy Strategic Network (WESNet) (which is a Canada wide research network, funded by industry and the Natural Sciences and Engineering Research Council of Canada (NSERC)) for funding this research.

\section{REFERENCES}

[1] Introduction to the Ramea Island, [Online]. Available: http://www.ramea.ca/. [Accessed 30-01-2013].

[2] CANMET Energy, "Natural Resource Canada," Natural Resource Canada, 07-07-2007. [Online].Available: http://canmetenergy.nrcan.gc.ca/renewables/wind/464. [Accessed 30-01-2013].

[3] M. Oprisan, "IEA Wind," IEA Wind - KWEA Joint Workshop, 01-04-2007. [Online].Available: http://www.ieawind.org/wnd_info/KWEA_pdf/Oprisa n_KWEA_.pdf. [Accessed 3001 2013].

[4] T. Iqbal, "Feasibility Study of Pumped Hydro Energy Storage for Ramea Wind-Diesel Hybrid Power System," The Harris Centre, St. John's, 2009.

[5] D.-J. Lee and L. Wang, "Small-Signal Stability Analysis of an Autonomous Hybrid Renewable Energy Power Generation/Energy Storage System Part I: Time-
Domain Simulations," IEEE TRANSACTIONS ON ENERGY CONVERSION, vol. 23, no. 1, pp. 311-320, 2008.

[6] Md. Rahimul Hasan Asif and Tariq Iqbal, "A novel method to model a hybrid power system with pumped hydro storage for Ramea, Newfoundland", IEEE, Newfoundland Electrical and Computer Engineering Conference, St. John's, 2012

[7] A. G. Rodríguez, A. G. Rodríguez and M. B. Payán, "Estimating Wind Turbines Mechanical Constants," in INTERNATIONAL CONFERENCE ON RENEWABLE ENERGIES AND POWER QUALITY (ICREPQ'07), Bilbao, 2007.

[8] Windmatic, "Windmatic 15s," [Online]. Available: http://windmatic.com/15s-brochure.pdf. [Accessed 30 $012013]$.

[9] Northern Power Systems, "Northern Power 100," [Online]. Available: http://www.northernpower.com/pdf/NPS100-

21_SpecSheet_EU-A4_English_2012.pdf. [Accessed 10 01 2013].

[10] Advantica Inc., "Moment of Inertia and Pump Startup/Failure," 1403 2011. [Online].Available: http://my.advanticagroup.com/support/allsecure/water secure/releases_advisories/KBA_pump_moment_of_in ertia.pdf. [Accessed 3001 2013].

[11] "The Engineering Toolbox," [Online]. Available: http://www.engineeringtoolbox.com/minor-losscoefficients-pipes-d_626.html. [Accessed 3001 2013].

[12] G. Brown, "Henry Darcy and His Law," 22062000. [Online]. Available: http://biosystems.okstate.edu/darcy/index.htm.

[Accessed 3001 2013].

[13] Renewables First, "Pelton \& Turgo Turbines," Renewables First, [Online]. Available: http://www.renewablesfirst.co.uk/pelton-and-turgoturbines.html. [Accessed 3001 2013].

[14] Chen, H., Cong, T., Yang, W., Tan, C., Li, Y., and Ding, Y., Progress in electrical energy storage system: a critical review. Progress in Natural Science 19 (2008), 291-312. 